Portland State University

PDXScholar

Dissertations and Theses

Dissertations and Theses

Winter 3-21-2017

\title{
Food Access Narratives in Southeast Portland, Oregon
}

Gwyneth Genevieve McKee Manser

Portland State University

Follow this and additional works at: https://pdxscholar.library.pdx.edu/open_access_etds

Part of the Food Security Commons, and the Food Studies Commons Let us know how access to this document benefits you.

\section{Recommended Citation}

Manser, Gwyneth Genevieve McKee, "Food Access Narratives in Southeast Portland, Oregon" (2017). Dissertations and Theses. Paper 3510.

https://doi.org/10.15760/etd.5394

This Thesis is brought to you for free and open access. It has been accepted for inclusion in Dissertations and Theses by an authorized administrator of PDXScholar. Please contact us if we can make this document more accessible: pdxscholar@pdx.edu. 
Food Access Narratives in Southeast Portland, Oregon

by

Gwyneth Genevieve McKee Manser

A thesis submitted in partial fulfillment of the requirements for the degree of

Master of Science

in

Geography

Thesis Committee:

Barbara Brower, Chair

Britt Crow-Miller

Nathan McClintock

Hunter Shobe

Portland State University

2017 
(C) 2017 Gwyneth Genevieve McKee Manser 


\begin{abstract}
Since the late 1990's, 'food deserts' have dominated the academic and policy literature on food access and food security. Food deserts are defined as areas that lack easy access to fresh, healthy, and affordable food, and are typically measured using Geographic Information Systems and spatial data sets. However, while food deserts may provide a useful measure for identifying food insecurity at a broad scale, they fail to account for individual definitions and perceptions of food access (Barnes et al. 2015; McEntee 2009). Furthermore, the food desert model assumes a lack of agency on the part of low-income populations (Alkon et al. 2013), and ignores other factors of food access, such as walkability, grocery store safety, customer service, and personal preference.

In this research, I examine the food access perceptions of residents, non-profit employees, and business owners in the Lents neighborhood of Portland, Oregon. Although Lents is classified as a food desert, there are also an abundance of ethnic grocers and specialty markets within the neighborhood. These grocers reflect the neighborhood's racial and cultural diversity, and are often overlooked by the spatial datasets typically used to measure food access. The research that I conducted in Lents revealed a disconnect between how the residents I interviewed perceive their food environment, and how government, non-profits employees, and business owners within the neighborhood view local food access. The findings underscore the importance of factors other than physical proximity when measuring food access, and also show the importance of ethnic and specialty markets in the landscape. These findings support the assertion that binary measures of food access often fail to capture the complexities of individual perceptions of food access (Alkon et al. 2013).
\end{abstract}




\section{Dedication:}

To my father, whose curiosity, wit, and bravery have inspired a lifelong love of learning. 


\section{Acknowledgements:}

I would like to thank my advisor, Barbara Brower, for her tireless enthusiasm, support, and patience. I would like to thank my committee, Hunter Shobe, Nathan McClintock, and Britt Crow-Miller, for their encouragement, time, and guidance. I would like to thank my partner, Amiana, for her loving support and her keen editing eye. I would also like to thank my family for their love and encouragement throughout this process. Furthermore, I would like to thank my cohort, Zuriel Rasmussen, Dirk Kinsey, Ryan Pemberton, Kevin Donohue, Zach Herzfeld, and Debbie Blackmore, for their friendship and scholarly advice. Finally, I would like to thank all of the participants who so generously donated their time to contribute to this research. My thesis would not exist without you. 


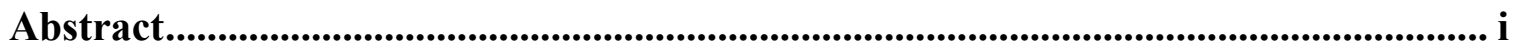

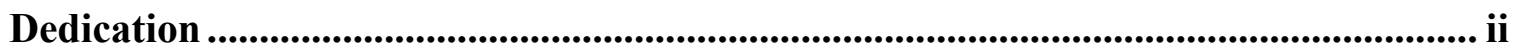

Acknowledgements ................................................................................................................ iii

List of Tables ................................................................................................................... vi

List of Figures................................................................................................................ vii

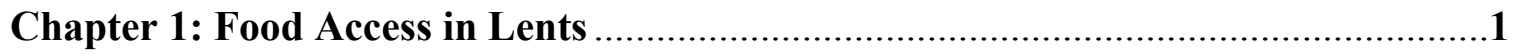

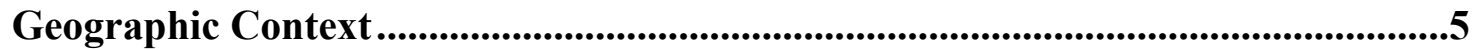

The Lents Foodscape .......................................................................................6

Neighborhood Demographics .............................................................................7

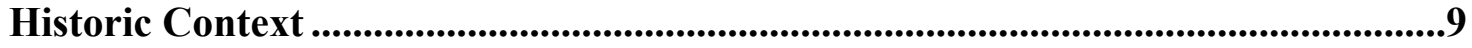

Research Statement ....................................................................................................13

Chapter 2: Health, Wealth, and Equity: Food Access in the Academic Literature ..15

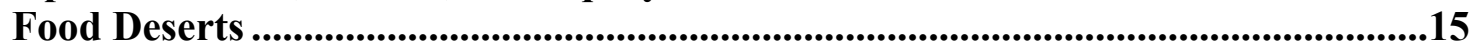

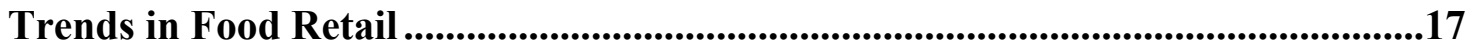

The Food Access Lexicon: Deserts, Swamps, and Jungles....................................20

Common Themes in Food-Access Literature ...............................................................22

Critiques of Research About Food Access ............................................................25

Chapter 3: Study Objectives and Design ..................................................................29

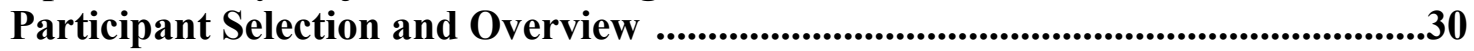

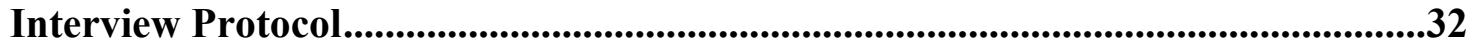

Data Analysis..........................................................................................................33

Chapter 4: Results.....................................................................................................35

Group A: Interview Themes ...............................................................................35

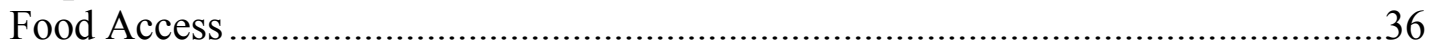

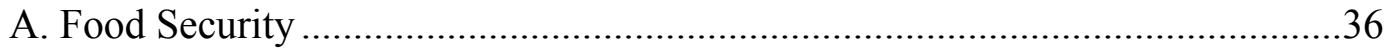

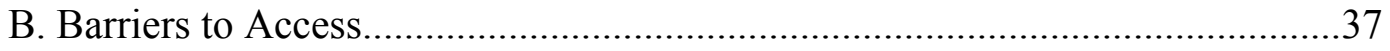

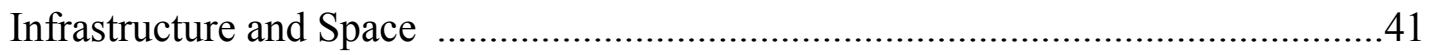

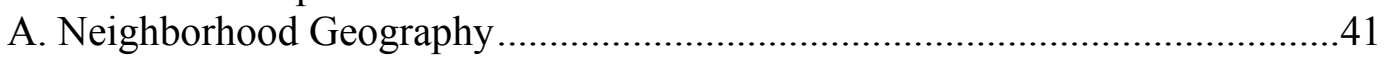

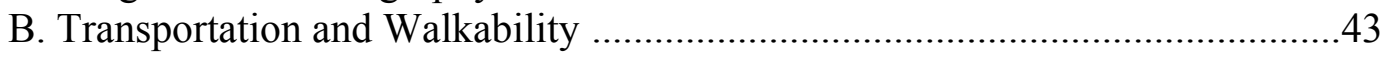

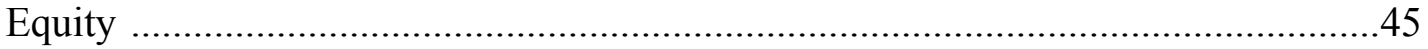

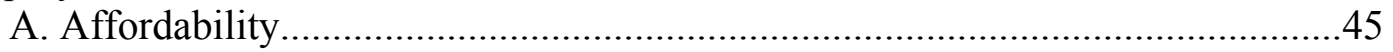

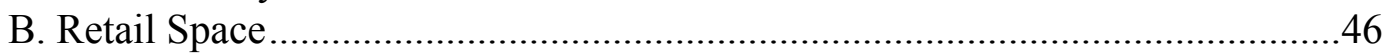

Results: Group B..........................................................................................................48

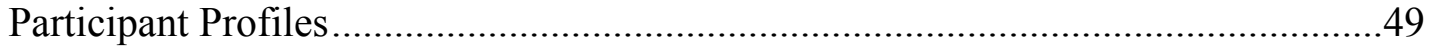

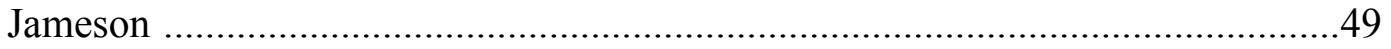

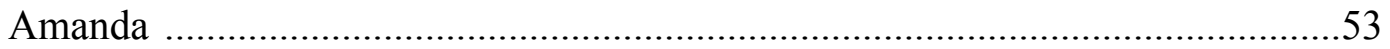

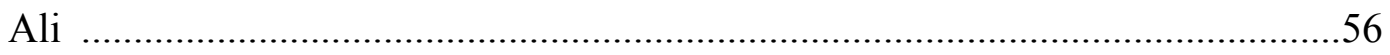

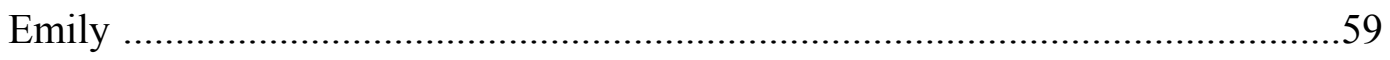

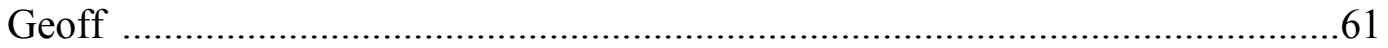

Group B: Interview Themes .....................................................................................64 


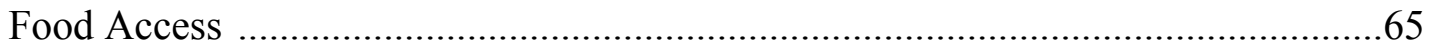

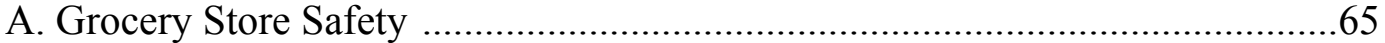

B. Specialty and Ethnic Grocers ........................................................................66

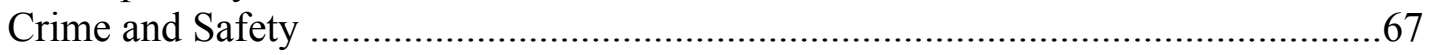

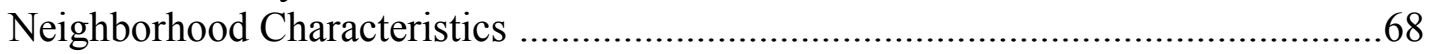

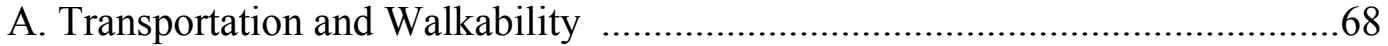

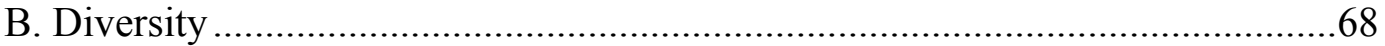

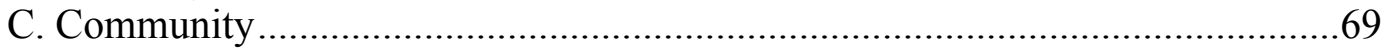

D. Neighborhood Change ...........................................................................69

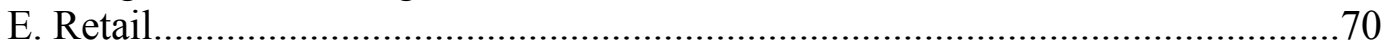

Chapter 5: Discussion ..................................................................................................71

Chapter 6: Conclusion ...................................................................................................................80

Limitations and Future Directions ...................................................................82

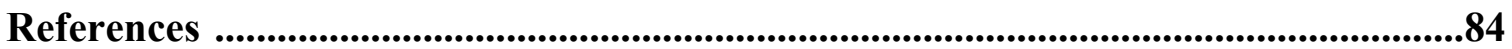

Appendices......................................................................................................................................92

Appendix A: Map of Lents-Area Grocers .......................................................92

Appendix B: Interview Questions, Group A ............................................................93

Appendix C: Interview Questions, Group B ............................................................94

Appendix D: Survey, Group B ......................................................................96 


\section{List of Tables}

Table 3.1 Group A interview participants' names, organizational affiliation, and role... 30

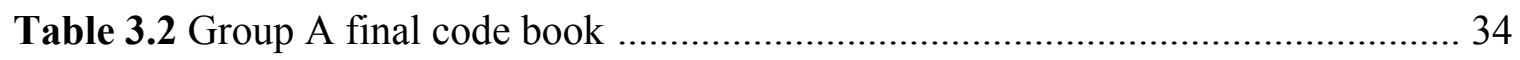

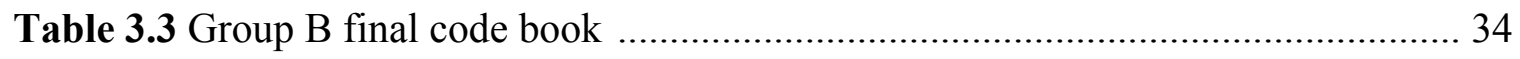

Table 4.1 Participant interview and survey overview (Jameson)............................... 49

Table 4.2 Participant interview and survey overview (Amanda) ................................ 53

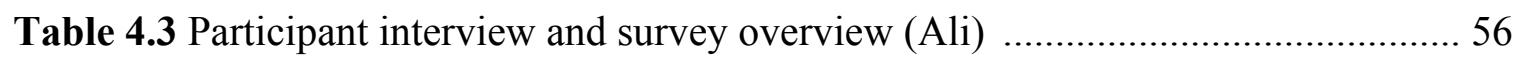

Table 4.4 Participant interview and survey overview (Emily) ................................... 59

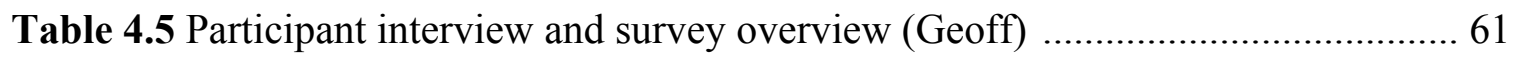




\section{List of Figures}

Figure 1.1 Food Access Research Atlas map of Portland, with map inset of Lents

Figure 1.2 Goods for sale at Stop N Save Convenience Store, located at 7720 SE Foster

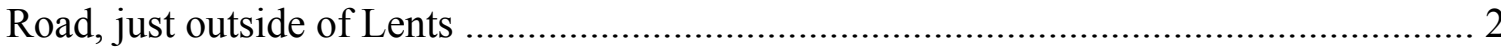

Figure 1.3 The Lents International Farmers Market at SE $91^{\text {st }}$ Ave and SE Foster Road is held each Sunday, and runs from summer to fall......................................................... 3

Figure 1.4 A map of Portland, with Lents inset map that highlights the neighborhood boundaries, and the Lents Town Center

Figure 1.5 Signs in Russian, Vietnamese, and Spanish welcoming shoppers to the Lents International Farmers Market

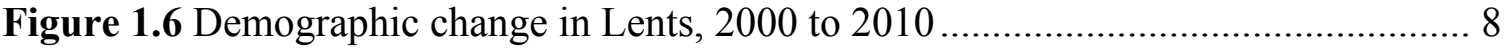

Figure 5.1 Image of the I-205 highway, as seen from the I-205 Multiuse Path 75 


\section{Chapter 1: Food Access in Lents}

According to the United States Department of Agriculture (USDA), Southeast

Portland has an "eating disorder."

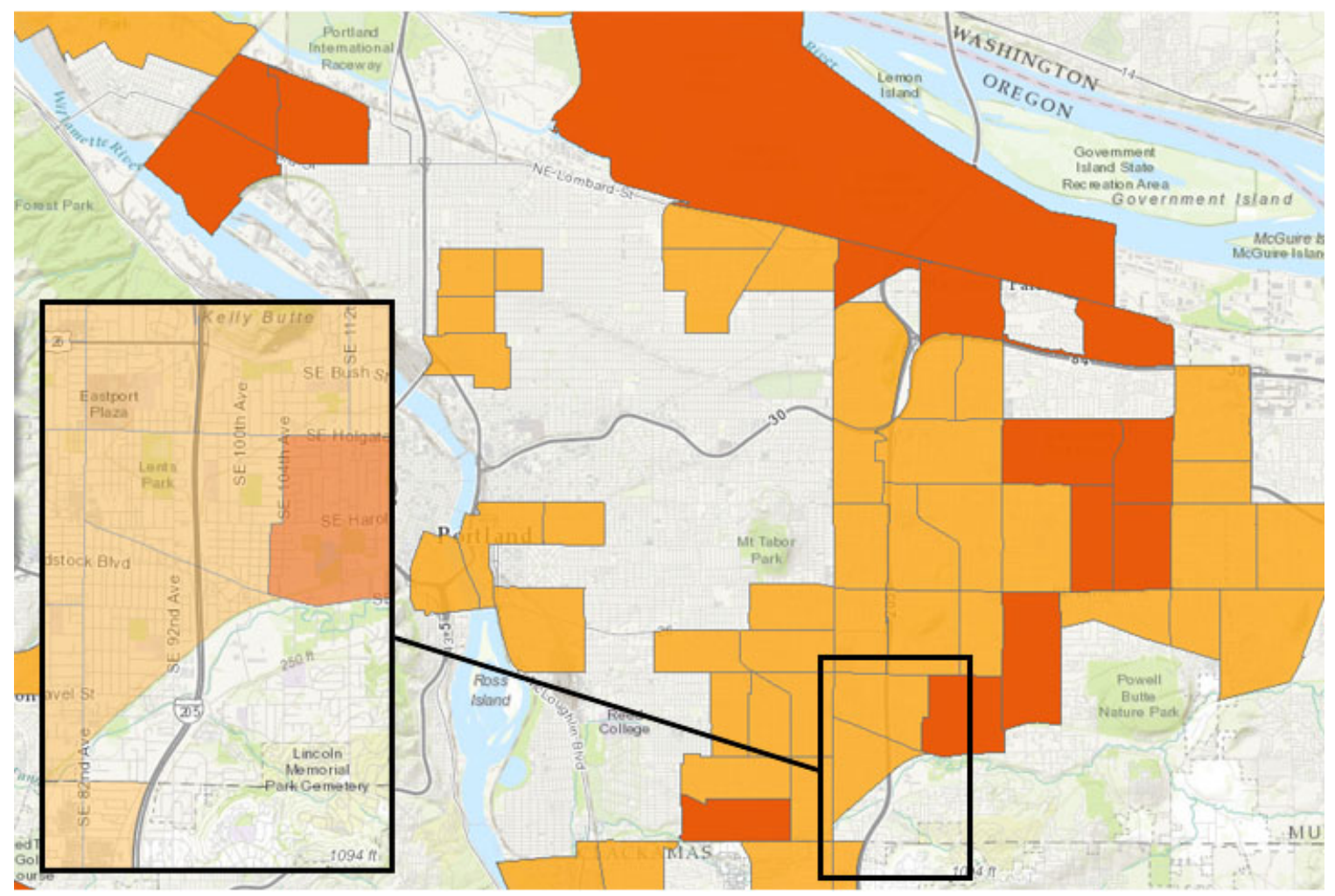

Figure 1.1 Food Access Research Atlas map of Portland, with map inset of Lents. Dark orange indicates low-income census tracts where a significant number of residents are more than a mile from the nearest grocery store, while mid-range orange indicates low-income census tracts where a significant number of residents are more than a mile from the nearest grocery store. Data are from the ERS and USDA, 2014.

The USDA's Food Access Research Atlas (FARA), which presents a spatial overview of food access across the United States, paints Southeast Portland neighborhoods like Lents in fiery shades of red and orange, thus indicating areas where low-income Portland residents have limited access to healthy and affordable food (Figure 1.1). A drive around the neighborhood seems to tell a similarly sobering story: run down auto body shops and fast food restaurants line the main streets, public transportation operates infrequently, and crumbling sidewalks end abruptly in inconvenient locations. 
Convenience stores hawk cigarettes and energy drinks, using bold fonts and bright colors to advertise their low prices on sugary snacks (Figure 1.2). Although many of the neighborhood's abundant corner stores also carry staples such as milk and eggs, the prices are typically high, and produce is rarely found among the aisles of Twinkies, beer, and beef jerky.

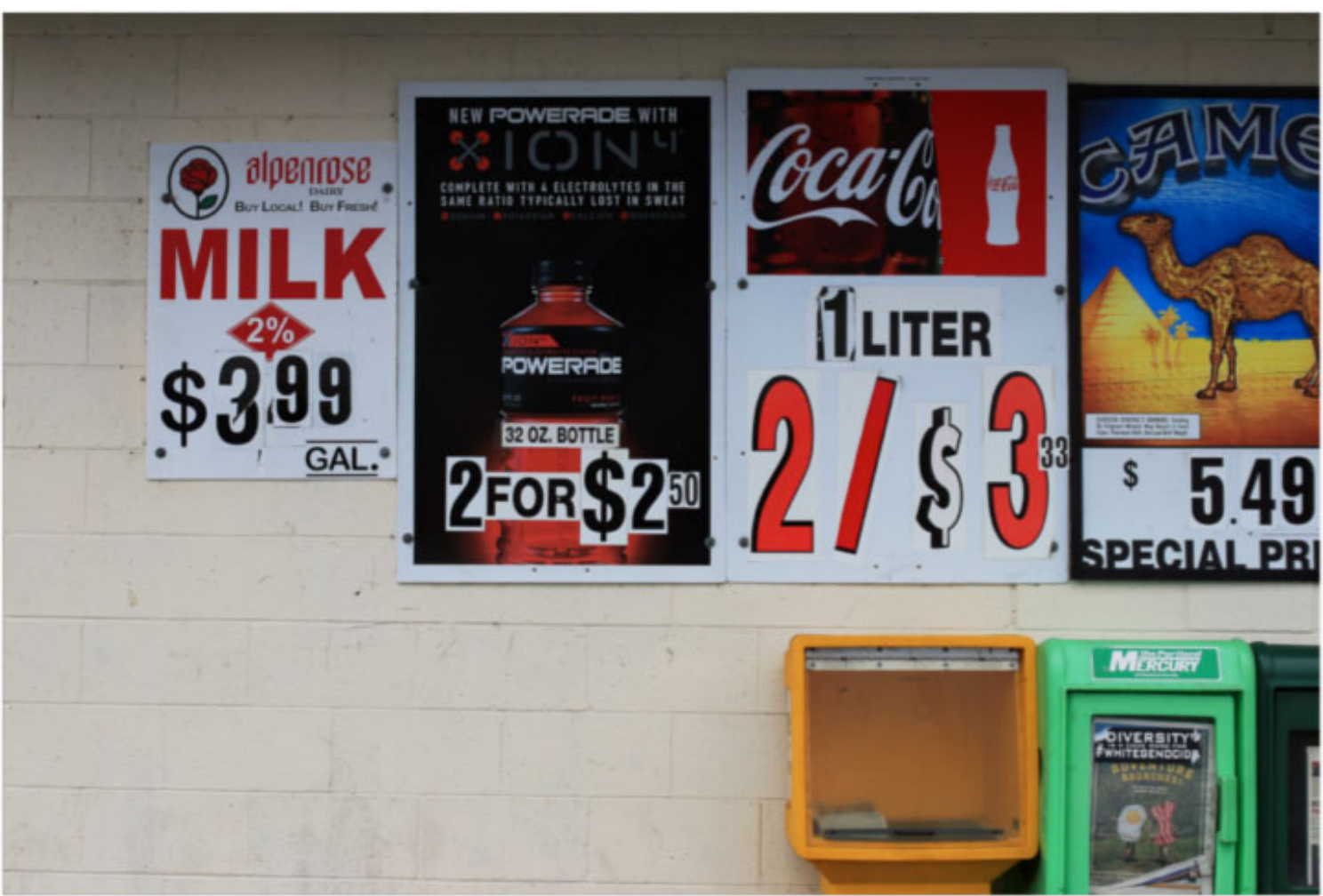

Figure 1.2 Goods for sale at Stop N Save Convenience Store, located at 7720 SE Foster Road, just outside of Lents (Shobe and Manser, 2016).

In many ways, Lents seems to be representative of the typical American food desert. In Portland, Oregon, a city that prides itself on its culture of sustainable food and "green" infrastructure (Goodling et al. 2015; McClintock et al. 2016), Lents is also an example of the deep disparities between rich and poor, white people and people of color (POC). It is no accident that the places that are least likely to have access to fresh, healthy, and affordable food are also the most likely to be low income and racially 
diverse, as these are the areas least likely to be able to mobilize the social and investment capital needed to attract retailers (Blanchard and Matthews 2007; McClintock 2011).

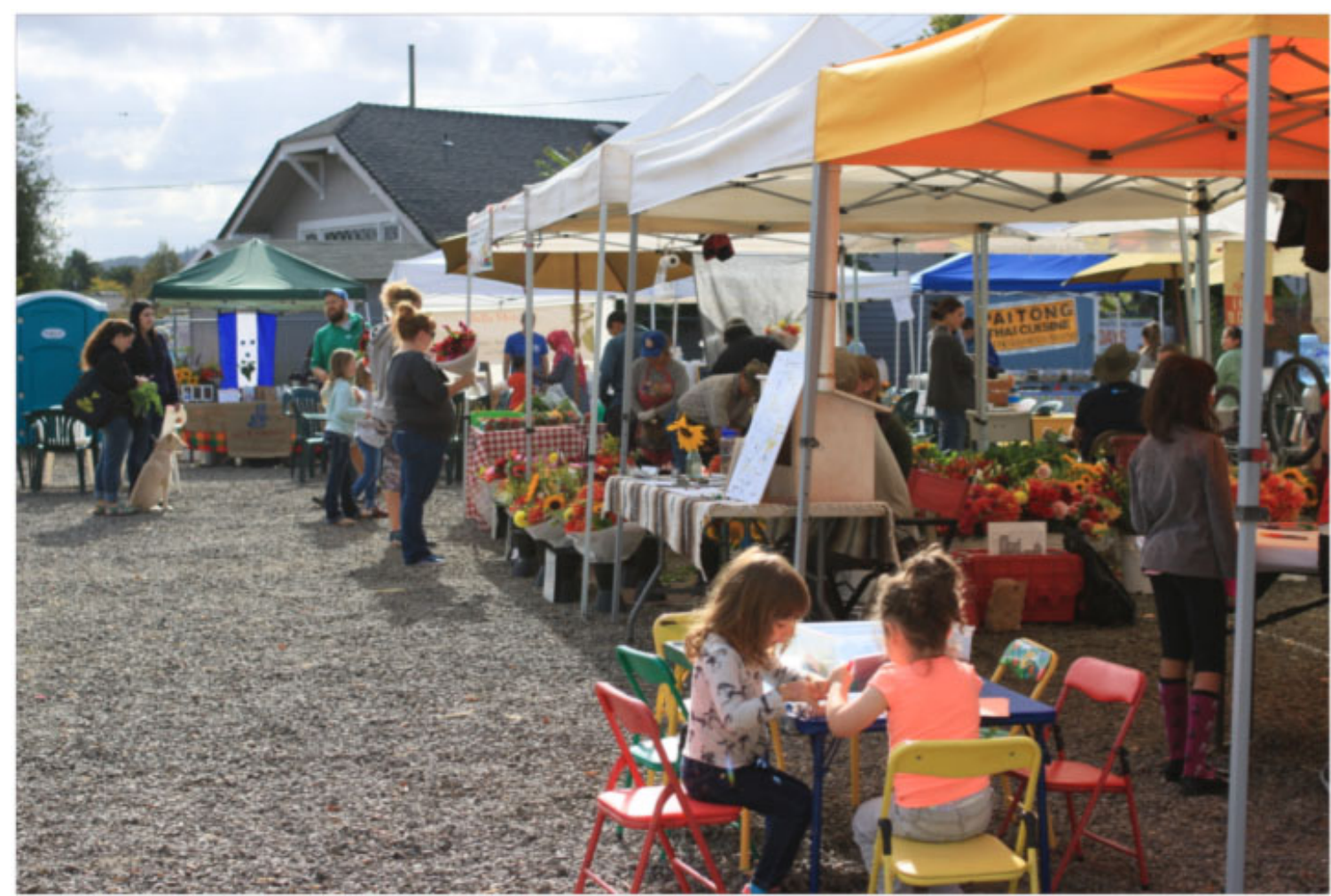

Figure 1.3 The Lents International Farmers Market at SE $91^{\text {st }}$ Ave and SE Foster Road is held each Sunday, and runs from summer to fall.

Despite these challenges, the neighborhood's foodscape is not as barren as the statistics indicate. Ethnic grocery stores line many of the neighborhood's main arteries, providing access to both culturally important foods and invaluable community spaces for the neighborhood's Asian and Hispanic/Latino populations, which are far larger than those of Multnomah County as a whole. With names like Good Neighbor European Deli and Oriental Food Value, these stores serve a burgeoning immigrant community, and are a critical part of the fabric of everyday life in many of Portland's southeast neighborhoods. Pop-up produce stands and produce "peddlers" deliver fresh produce to 
underserved populations and busy families, community and backyard gardens abound, and a weekly farmers market in summer and early fall bring farmers from across Portland's Willamette Valley and beyond into the neighborhood (Figure 1.3). While the neighborhood appears to face many challenges to food access, there are also many people in the community who are working to make the community's foodscape more vibrant, diverse, and accessible.

This research seeks to test the unity of the rigid definition of food access imposed by the umbrella term "food desert" by exploring food access within the context of Portland's Lents neighborhood. Through a small sample of interviews with residents, businesses, and non-profits within the neighborhood, I illustrate the richness and complexity of neighborhood food access, and the limitations of the food desert model. While GIS tools such as the USDA's FARA offer a powerful means of investigating food access issues on a large scale, they fall short when it comes to community input. This thesis attempts to bridge the gap between quantitative and qualitative data by using spatial tools such as the USDA's FARA to drive interview-based research that problematizes the assumptions made from big data. 


\section{Geographic Context}

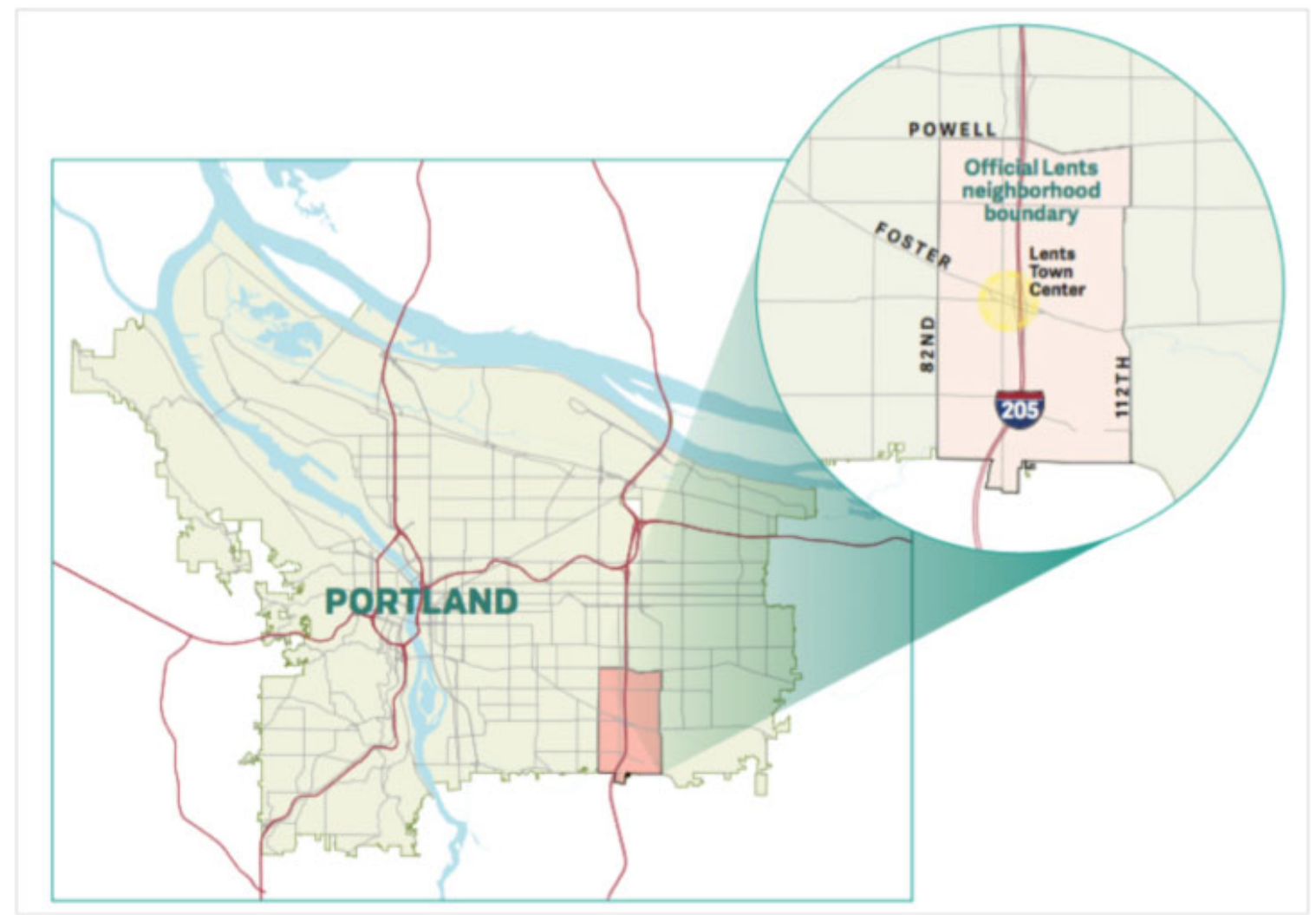

Figure 1.4 A map of Portland, with Lents inset map that highlights the neighborhood boundaries, and the Lents Town Center (Brunelle, et al. 2016).

In many ways, the major transportation arteries that run throughout the neighborhood are what define Lents, which is located in Southeast Portland. While most neighborhoods that border the city's major interstates use the roads as de facto neighborhood boundaries, Lents is bisected by I-205, and the highway and Foster Road effectively split the neighborhood into four quadrants (Figure 1.4). The neighborhood is one of the city's largest, at approximately 3.75 square miles, and it crosses county boundaries; the southernmost section of the neighborhood is located in Clackamas County, while the remainder of Lents is situated within Multnomah County. Surrounding Lents are the neighborhoods of Foster-Powell, Mt. Scott-Arleta, and BrentwoodDarlington to the west, Powellhurst-Gilbert to the north and the east, and Pleasant Valley 
to the east. Powellhurst-Gilbert and Lents share a section of overlapping neighborhood boundary, which is located in the northeast section of Lents.

\section{The Lents Foodscape}

The Lents neighborhood is served by a number of supermarkets, corner stores, and large ethnic grocers that are distributed unevenly across the landscape. The majority of such stores are clustered in the north- and southwestern quadrants of the neighborhood, near major road intersections. A Walmart sits within the neighborhood boundaries at $4200 \mathrm{SE} 82^{\text {nd }}$ Ave, and serves the northwestern quadrant of the neighborhood. Located just north of the Walmart (and outside the neighborhood's borders) are WinCo, a regional low-cost grocer, and Fubon, a large Asian grocer. Farther south, a Fred Meyer is located at $5253 \mathrm{SE} 82^{\text {nd }}$ Ave, and across the street are Portland Fruit West, a low-cost produce store, and Oriental Food Value, a large Asian grocer.

In Lents' southwestern quadrant, all of the major grocery store chains are located outside the neighborhood's boundaries. Although there are a multitude of options, including a Grocery Outlet Bargain Market, Fred Meyer, Trader Joes, and another Walmart (see Appendix A), some are over a half mile from Lents. The part of the neighborhood that falls east of I-205 has significantly fewer large grocery store options. A Safeway serves the northeastern section of the neighborhood; however, it is located nearly a half mile east of Lent's easternmost border. The southeastern section of the neighborhood lacks a nearby grocery store altogether. 


\section{Neighborhood Demographics}

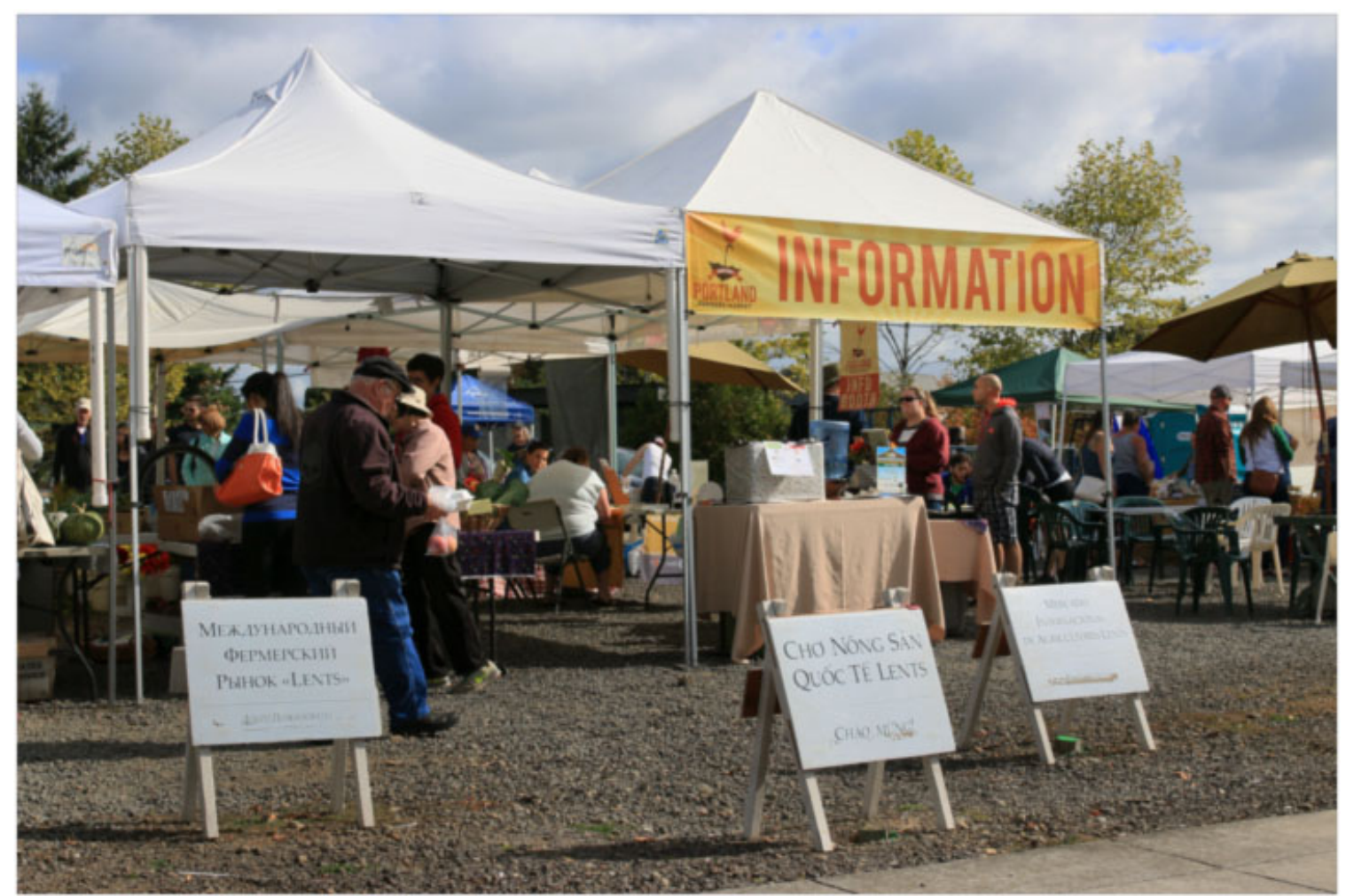

Figure 1.5 Signs in Russian, Vietnamese, and Spanish welcoming shoppers to the Lents International Farmers Market.

A drive down one of the main streets in Lents offers a glimpse into an ethnically and culturally diverse community. Signs in Spanish, Korean, Vietnamese, Mandarin, and Russian abound, calling attention to the fact that Lents is one of the most ethnically and linguistically diverse areas in the Portland Metropolitan Area (Figure 1.5). The neighborhood has a significantly higher proportion of minority residents than the remainder of the city and, according to the 2010 United States Census (Office of Neighborhood Involvement 2011), the demographics of the neighborhood are shifting (Figure 1.6). In 2000 the white population accounted for $73.9 \%$ of the neighborhood, but by 2010 it dropped to $60.2 \%$. This number is in sharp contrast to the average for Multnomah County as a whole, which was 76.5\% Caucasian in 2010. In the last ten years 
Lents' total population has swelled by $10 \%$, and in that time the Black and African American population rose by nearly $200 \%$, the Asian population rose by over $75 \%$, and the Hispanic and Latino population rose by nearly $70 \%$. The American Indian and Alaskan Native population also rose by $24 \%$, and the Native Hawaiian and Pacific Islander population rose by nearly 40\% (Office of Neighborhood Involvement 2011). Interestingly, while Hispanic/Latino and Asian/Pacific Islander populations exceed the average for Multnomah County, only $4.5 \%$ of the neighborhood's population identifies as Black or African American, which is slightly below the county's 2010 average of 5.6\%.

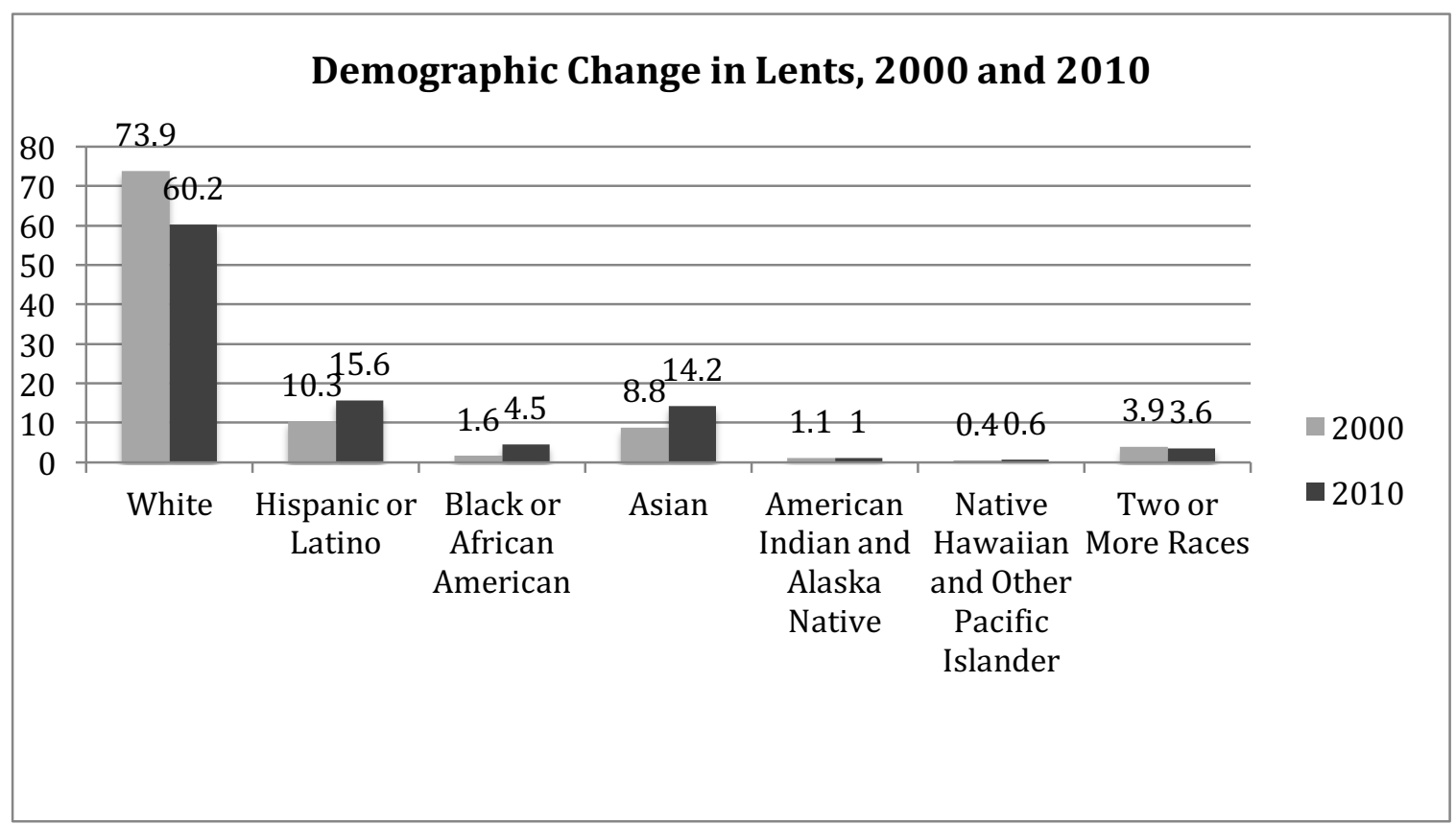

Figure 1.6 Demographic change in Lents, 2000 to 2010. Values are given as percentages of the neighborhood's total population. Census data were provided by the Office of Neighborhood Involvement (2011).

Lents' exceptional demography translates to unusually high linguistic and cultural diversity within the neighborhood. In the 1990's Southeast Asians made up the largest and fastest growing ethnic group, followed by Hispanic/Latino and Eastern European 
populations (Portland State University 1993). These trends largely hold true today. Census data show that Lents also has one of the highest proportions of foreign-born residents in all of Portland, exceeded only by the nearby neighborhoods of Mill Park, Powellhurst-Gilbert, and Hazlewood (Cedar Lake Ventures, Inc., 2016). The majority of foreign-born residents, who make up $23.3 \%$ of Lents' total population, are from Vietnam (21.4\%), Mexico, (19.5\%), China (16.5\%), Russia (8.8\%), Ukraine (3.6\%), and the Philippines (3\%) (Cedar Lake Ventures, Inc., 2016). The linguistic and cultural diversity of the neighborhood is also reflected in businesses and services in the area.

\section{Historic Context}

When it was first platted in 1892 Lents was more than a mile outside of Portland's city boundary and the town operated independently until 1912, when it was annexed by the city of Portland. Lents initially gained popularity as one of its main thoroughfares, Foster Road (which runs northwest to southeast through the center of the neighborhood), became an increasingly traveled farm-to-market route. This steady flow of traffic led to the eventual creation of a bustling business district along Foster and 92nd Avenue, still a popular neighborhood destination today (Portland State University, 1993).

A report by Portland State University in the early 1990's captured many people's present-day attitudes towards the neighborhood, concluding: "Lents' current status is that of a formerly vital neighborhood now in a state of decline" (Portland State University 1993: 4). Much of that decline has been attributed to the development of Interstate 205, built in the 1970's. The construction of I-205 effectively cut the neighborhood in half, dividing the eastern and western portions. The University's report further cites the loss of 
a "pedestrian-friendly environment" (Portland State University 1993: 4) as one of the primary drivers of neighborhood decline. As walkability and parking decreased following the freeway construction, the neighborhood's residents increasingly came to rely on cars, which took them outside of the neighborhood for their shopping needs. This stifled Lents' economic growth, and caused many of the businesses to relocate outside of the neighborhood core (Portland State University 1993).

The late ' 90 s should have been a major turning point for the neighborhood. In 1998 the Portland Development Commission (PDC) declared the Lents Town Center ${ }^{1}$ an Urban Renewal Area (URA). At the time this seemed a huge boon for the struggling community; the PDC is a government agency that focuses on economic growth and urban renewal, so residents expected their neighborhood to once again become a thriving business district with desirable amenities. However, although the PDC has invested nearly $\$ 100$ million city dollars into neighborhood urban renewal and social equity projects (Mesh 2014), their efforts have yet to bear much fruit. Attempts to establish an Eastern European bakery in the neighborhood failed, and long-term negotiations with major grocery retailers, including Whole Foods, have fallen through, costing taxpayers millions and further diminishing neighborhood morale (Mesh 2014).

Today, despite continued efforts by the PDC, the neighborhood continues to struggle with many of the problems it had in previous decades. The Lents Town Center has remained largely undeveloped, and neighborhood's major transit hub is still "noisy, malodorous, and lacking in pedestrian comfort and safety" (Gulizia et al. 2006: 15). Although the city recently spent a million dollars on surfacing unpaved streets in the

\footnotetext{
${ }^{1}$ The Lents Town Center, roughly located at SE Foster Road and $92^{\text {nd }}$ Avenue, is a prominent business district in the neighborhood, and the site of significant future neighborhood development.
} 
neighborhood, it has also invested over $\$ 2.6$ million in bioswales and sidewalks that run along vacant storefronts, and end abruptly in inconvenient locations (Mesh 2014).

Many of the community's social and developmental ills can be traced to the city's lack of investment in Lents. The neighborhood's abundance of empty lots, vacant properties, and parking lots has long created barriers to economic and community revitalization (Gulizia et al. 2006). In recent years these spaces have become the focus of additional neighborhood ire, as homeless camps have taken over much of the vacant land and green space in Lents. In particular, Johnson Creek, the Springwater Corridor, Beggar's Tick Wildlife Refuge, and Lents Park ${ }^{2}$ have become areas of contention between the neighborhood's residents and its homeless population ${ }^{3}$ (Green Lents 2016; Hernandez 2016; Templeton 2016). After months of attempting to get the attention of city officials, one resident expressed her frustration with the problem, saying: "nobody's doing anything, because it's Lents" (Smith 2016). While these sentiments reflect a growing concern about the neighborhood's homeless population, they also indicate increasing dissatisfaction and hopelessness around the city's commitment to the neighborhood.

Based in part on the experiences of other neighborhoods in Portland, resident concerns have also come to center around gentrification and affordability. A city report

\footnotetext{
${ }^{2}$ There are number of green spaces within Lents, including Lents Parks, Bloomington Park, Ed Benedict Park, Glenwood City Park, and Beggar's Tick Wildlife Refuge. There are also two multi-use paths in the neighborhood: the I-205 Multi-Use Path and the Springwater Corridor. The I-205 Multi-Use Path runs north to south along the I-205 transit corridor, and is a walking and biking path. The Springwater Corridor is also a multi-use pathway for bikers and walkers, and it runs east to west through the southern section of the Lents neighborhood. It roughly follows the path of Johnson Creek, and is the southeastern section of the larger 40 Mile Loop, which connects large parts of the city.

${ }^{3}$ In September of 2016, as the homeless population along the Springwater Corridor reached critical mass, the City of Portland conducted a "sweep" of the trail in order to remove illegal encampments. An estimated 600 people were displaced (Roth 2016).
} 
published in 2013 found that Lents was susceptible to a wave of gentrification sweeping down Portland's 82nd avenue, which is one of the neighborhood's main thoroughfares (Bates 2013; Griffin 2013). A recent article by Thrillest, an online media group, named Lents one of the "next big neighborhoods in America," and the neighborhood's steadily increasing rents and housing prices reflect the broad-scale changes that are slowly coming to the area (Becker 2015). In a neighborhood once known for its affordable housing things are changing, and low-income residents feel these changes most poignantly. A neighborhood study suggests that, "regardless of race or ethnicity, lowincome households making $\$ 39,720$ — the threshold for $60 \%$ of median family incomecan no longer afford to rent the average 2-bedroom apartment in the neighborhood and may have to settle for a single bedroom or risk accruing debt, foregoing other critical needs, or relying on the help of others to remain in place" (Green Lents 2016).

As demonstrated above, the Lents neighborhood is in transition. Changes are currently underway within the neighborhood, but their pace is often slow and their value is not always clear to current residents. Issues such as walkability and transportation access can be traced back to the city's lack of interest in the neighborhood, and its decision to build a freeway through the heart of the community. Conversely, problems such as housing affordability and homelessness reflect wider changes taking place throughout the city of Portland. Ultimately, these issues reflect the city's historic lack of investment in the neighborhood, and an increasing recognition of the need for change. 


\section{Research Statement}

There is an increasingly urgent need for research that combines both quantitative and qualitative methodologies that together can paint a more nuanced picture of food access in particular locations, and help to drive policy measures to address equity issues. At present, much of the political and academic work that focuses on food access issues makes extensive use of tools such as Geographic Information Systems (GIS), which relies on broad tools of analysis and data sources that are often inaccurate (Ma et al. 2013). Even at their best, these results may not reflect peoples' perceptions of their food environment, whether positive or negative (Barnes et al. 2015; McEntee 2009). Largescale research efforts, such as the United States Department of Agriculture's FARA, which uses GIS as a means of "formalizing, identifying, and defining areas of low food access," may also invalidate the experiences of people who do not fit the state's framework for adequate food access (Agyeman and McEntee 2014: 215). At the same time, the USDA's FARA serves to promote market-based solutions, in the form of supermarkets, to problems with significantly deeper roots, such as poverty and racial injustice (McClintock 2011).

In an effort to address the relative lack of qualitative research on food-access issues, my research explores current perceptions of food access in the Lents neighborhood, as conceptualized by residents, nonprofits, and business owners in the area. I address the following questions: How do residents perceive their food access, and how does that align with government and nonprofit perceptions of food access in the neighborhood? What role, if any, do ethnic and specialty food markets play in the neighborhood foodscape? Based on previous research and knowledge of the 
neighborhood, I hypothesize that although government organizations and business owners and non-profits working in the area identify Lents as a food desert, not all residents feel that their access to food resources is inadequate. Further, I predict that culturally specific and specialty grocers in and around the neighborhood are an important, and overlooked, food resource within the neighborhood.

In order to test these hypotheses, I conducted substantive, semi-structured interviews with both residents and food security-oriented businesses and non-profits within the neighborhood. Businesses and non-profits were interviewed in order to get a sense of how food access is being framed by advocates working in Lents. Residents were interviewed in order to assess the perceptions of people who live in the neighborhood, and to see if resident narratives match the perceptions by non-profits and businesses within the area. In the following chapters I describe: (1) the academic literature on food access; (2) the study area; (3) the study intent and design; (4) results and conclusions, and (5) study limitations and areas for future research. 


\section{Chapter 2: Health, Wealth, and Equity: Food Access in the Academic Literature}

An analysis of food-access research shows a consensus among policy makers and academics: equity issues and shifting retail patterns have shaped a contemporary foodscape that is characterized by a patchwork of "... privilege and poverty, Whole Foods and whole food deserts" (McClintock 2011, 90-91; Shobe and Manser 2016). In high-income countries food access is typically explored through the lens of "food deserts," a term that first emerged in Scotland in the early 1990s. The term was initially used to describe areas where residents "lacked access to an affordable and healthy diet" owing to a lack of grocery retailers (Cummins and Macintyre 2002; Beaulac et al. 2009; Blanchard and Matthews 2007). As food access research has evolved, it has also come to integrate a more complex range of issues above and beyond geographic proximity to grocery retailers. Below, I examine the evolving definition of the term "food desert," the global retail trends that have shaped our current foodscape, and the lexicon of food access terms that emerged in the past thirty years. I then address common themes in the food access literature, as well as emerging critiques of food access research.

\section{Food Deserts}

In recent years food-access issues have emerged as a significant topic in public policy initiatives and academic research. However, there is still little consensus on what the term "food desert" means. Below, I review government and academic engagement with the term, and explore how food deserts are currently defined within the academic and policy literature. 
Although the term has been in wide use in academic literature since the late 1990s, the United States government was a relatively late adopter of the phrase "food desert." The term was officially defined first by the United States Congress, in the Food, Conservation, and Energy Act of 2008. In the Act, also known as the 2008 Farm Bill, food deserts were loosely classified as "area[s] in the United States with limited access to affordable and nutritious food, particularly such an area composed of predominantly lower income neighborhoods and communities" (U.S. Congress 2008, Title VI, Sec. 7527). The USDA later expanded this definition in a 2009 report in order to address questions that continue to shape academic and policy debate around food access. These questions include: "What is affordable food and nutritious food? What does it mean to have (or not have) access to such food? Do individuals or do areas lack access?" (Ver Ploeg et al. 2009, 1).

Interestingly, despite wide use of the phrase "food desert" among academics, there is still significant disagreement about the term's defining characteristics. In moving toward a concrete and more inclusive academic definition of "food desert," Shaw (2006) defines food access as a combination of ability (physical barriers to food purchases), assets (economic barriers to food purchases), and attitude (a state of mind that prevents consumers from accessing certain foods). Shaw's research maintains that the problem with food deserts is not so much the term "food desert" itself, but the nebulous classification system that was being used to research the issue.

As food access research has tried to expand the food desert concept, research and policy work increasingly take into account factors beyond simple geographic access to food, such as nutritional needs, economics (typically with a focus on low cost), and "the 
ability to acquire culturally appropriate food through local, nonemergency sources"

(Short et al. 2007; Lawson 2005, 270). Within this framework, backyard and community gardens, farmers markets, and cooperative grocery stores are seen as ways of improving equitable access to food at the neighborhood level (Lawson 2005). In theory, these efforts are the most likely to address the specific needs of different neighborhoods, but in practice such primarily grassroots efforts are rarely coordinated, making their total impact on community food security difficult to assess (Short et al. 2007). A review of the literature by Guszak Cerovečki and Grünhagen (2016) found the following common food desert characteristics: areas without food stores; areas in which stores are far away; areas with poor choice of fresh produce; and areas with residents who have specific socioeconomic characteristics, including low incomes and lack of vehicle access.

\section{Trends in Food Retail}

Abetted by the industrialization of agriculture and advances in technology, within the past century there have been massive changes to the ways that food is bought, sold, and produced around the globe. Since the emergence of the full service food market model in the 1920s and 30s, food retailers have moved towards a business model that is increasingly concentrated, globally sourced and operated, and large in size (Blanchard and Matthews 2007; Gottlieb and Joshi 2013). Fueled in part by increasing land needs, ever-tighter profit margins, white flight ${ }^{4}$, and the growth of the automobile, grocery

\footnotetext{
${ }^{4}$ Following white flight in the 1950 s and 60 s, the presence of food retailers in urban centers declined sharply as white middle-class suburban locations became the preferred venue for retailers. In recent years, as urban centers have been revitalized and "reactivated," grocery retailers have begun to return to the urban core (Padilla and Eastlick, 2009; Guszak Cerovečki and Grünhagen, 2015). As downtown areas are "rediscovered and renovated" (Leinberger, 2005), revitalization efforts often cater to the new, higher-
} 
stores have progressively moved into suburban neighborhoods, away from the urban core and rural centers (Gottlieb and Joshi 2013; McClintock 2011). The resultant food deserts and grocery gaps place an undue burden on low-income populations and communities of color, forcing them to either rely on convenience stores for their daily food needs ${ }^{5}$, or to travel long distances to access fresh, healthy, and affordable food (Shobe and Manser, 2016).

Grocery store mergers, such as Kroger's 1998 purchase of Fred Meyer, have had a lasting impact on the retail market. One of the major forces driving the consolidation of the food industry is globalization; and it is predicted that within the next few years fewer than six major retailers will dominate the global food market (Hendrickson et al. 2001). As a result, smaller processors and farmers are being forced out of the marketplace, since their economies of scale do not allow them to compete with larger national and international chains (Hendrickson et al. 2001; Carro-Figueroa and Guptill 2007). Twenty large grocery retailers now dominate the U.S. market, accounting for over $60 \%$ of grocery store sales, a 50\% increase in market share since the early 1990s (Elitzak 2015).

While corporate consolidation may lower costs for grocery retailers by increasing their economies of scale, these savings are generally not passed on to consumers (Sharkey and Stiegert 2006; Martinez 2007). Moreover, when mergers have led to more concentrated markets the result has been greater market power for the remaining supermarkets, leading to decreased price competition in the marketplace and food price

income residents who have begun to return to urban neighborhoods. As a result, food access issues in many downtown areas remain, particularly for lower income residents (Galvez et al., 2007).

${ }^{5}$ While convenience stores are an important part of the foodscape, consumers pay a premium at these locations, and these venues typically offer less variety and fewer healthful options (Blanchard and Matthews, 2007). 
increases for consumers (Sharkey and Stiegert 2006). Furthermore, increasing vertical integration, which links retailers, distributors, and processors, leaves smaller grocery retailers, such as mom-and-pop stores, shut out of key processing and distribution markets (Hendrickson et al. 2001). It has been shown that ethnically specific food stores, for example, are unable to compete with the bulk pricing of larger grocers. In gentrifying neighborhoods, sales are further hurt by the displacement of POC who make up the primary customer base for many of these culturally specific stores (Komakech and Jackson 2016).

In recent years, non-traditional food outlets have also emerged as a formidable market force. This is primarily due to the growing popularity of supercenters such as Walmart and Super Target, and warehouse clubs, such as Costco. Together, these largescale retailers accounted for $17.1 \%$ of home food expenditures in 2005 . These stores have encouraged consumer reliance on personal vehicles for grocery shopping; as a Brookings Institute report remarks, “[n]o one walks to a Sam's Club” (Leinberger, 2005). Conversely, traditional supermarkets accounted for $58.2 \%$ of grocery sales, and convenience stores accounted for $2.9 \%$ of grocery sales nation-wide (Martinez 2007). Another surprising source of food sales is drug and dollar stores, which together make up 8.7\% of food sales (Martinez 2007). In 2015, Dollar General, the leading dollar store retailer, was ranked 18th in grocery sales within the United States, while CVS Health, Walgreens, and Rite Aid were ranked 11th, 23rd, and 44th, respectively (Zwiebach 2015).

Although non-traditional retail formats have not typically been considered when assessing food access, their popularity clearly indicates that they deserve greater scrutiny 
within food access research ${ }^{6}$. Furthermore, while supermarkets and supercenters are often framed as offering the widest selection of goods at the lowest price, research shows the potential for small retailers to contribute to healthy and affordable food environments (Song et al. 2009; Glanz et al. 2007; Ortega et al. 2015). In a study to assess whether or not small-scale food retailers can contribute significantly to community food security, Short et al. (2007) found that small-scale retailers in the San Francisco Bay Area are able to offer a large selection of relatively low-cost goods while also meeting specific cultural demands.

As demonstrated above, recent trends in grocery retail have had a profound impact on the food landscape, both globally and in the United States. In particular, grocery store mergers have resulted in higher prices for consumers, and increasing competition for small retailers. Additionally, changes in overall consumer preferences have favored an increase in warehouse and superstore shopping. Furthermore, increasing reliance on "non-traditional" retail outlets calls attention to their lack of inclusion in much of the current academic research on food access.

\section{The Food Access Lexicon: Deserts, Swamps, and Jungles}

Within the past decade, food access researchers have coined a variety of terms to describe our twenty-first century foodscape. With their evocative imagery, terms like "food mirage," "food swamp," and "junk food jungle" bring to mind landscapes overrun

\footnotetext{
${ }^{6}$ Another emerging trend that deserves further inquiry is the growth in the home-delivery and mail-order food sector. In 2005, this retail category accounted for 4\% of grocery sales nationwide (Martinez 2007). Indicative of this change, Amazon.com was the $62 \mathrm{nd}$ most popular food retailer in the United States in 2015 (Zwiebach 2015). As the so-called "sharing economy" continues to expand into food services, businesses such as UberEATS and Instacart have the potential to account for an increasing percentage of grocery sales.
} 
with fast food or mired in unhealthy options, such as convenience stores. Below, I review the definitions of "food mirage," "food swamp," "food hinterland," and "junk food jungle," and these terms' use in the current academic literature.

The term "food mirage" was coined in 2007 by researchers attempting to critique the assumption that close proximity to full-service chain grocery stores results in undisputed food access and security (Short et al. 2007). In a food mirage, "full service grocery stores appear plentiful but, because food prices are high, healthful foods are economically inaccessible for low-income households" (Breyer and Voss-Andreae 2013: 131). Everett (2011) utilized the concept to illustrate the effect that price and access to culturally appropriate foods plays in food purchases made by Hispanic families in North Portland. While large grocery store chains are relatively abundant, the families interviewed found them to be expensive and lacking in culturally appropriate ${ }^{7}$ foods, thus necessitating long travel times to discount supermarkets elsewhere in the city. Everett's research highlights the increased burdens of time, distance, and cost, which can mean infrequent shopping trips and, as a result, less fresh produce (2011).

Additional research by Breyer and Voss-Andreae found that $13 \%$ of Portland's impoverished population lives more than one mile from a low-cost grocery store, whereas only $3 \%$ of the total population lives more than one mile from any type of grocer (2013). In their conclusion, Breyer and Voss-Andreae (2013) claim that Portland has relatively few food deserts; instead, the authors argue that the city has a large number of food

\footnotetext{
${ }^{7}$ Notably, Short et al. (2007) question the validity of using terms such as "culturally appropriate," based on the fact that it may not accurately reflect the needs of a wide variety of populations, such as African American communities and poor whites. This highlights the need to explore the concept of ethnic food stores and measures of "cultural appropriateness" in greater detail, particularly with respect to the academic literature.
} 
mirages and food "hinterlands," which have low food access but are not considered food “deserts" (Leete et al. 2012). However, according to the U.S. Department of Agriculture (USDA), large swaths of Northeast and Southeast Portland are classified as food deserts, which the USDA defines as low-income census tracts where a significant portion of residents are over a half mile away from the nearest grocery store. These areas also tend to correlate with populations that have limited vehicle access, and are thus highly reliant on public transportation in order to do their grocery shopping (ERS USDA 2014). This conflict emphasizes the need to further develop more nuanced approaches for examining food deserts so that these issues can be adequately addressed at a local level.

More recently, the term "food swamp" has also emerged to describe urban areas of low socioeconomic status where the overwhelming presence of calorie-dense snack foods inundates healthier food options, with implications for increased obesity and negative health outcomes (Ortega et al. 2015; Canton et al. 2015; Payne et al. 2015). However, food swamps are a relatively untapped research area that has the potential to further inform the academic literature on food access. Similarly, "junk food jungle" refers to areas with an excess of fast food and a lack of grocery stores and supermarkets (McClintock 2011).

\section{Common Themes in Food-Access Literature}

Lack of access to food is rarely a cut-and-dried issue, and food access can be related to a whole suite of other topics, such as race, income, and transportation justice. In this section, I examine three themes that are prevalent throughout the food access literature: physical access to stores, affordability, and health implications. 
Ease of access to food retailers, with respect to distance traveled and sufficient abundance of retailer types (e.g. supermarkets, convenience stores, etc.) has important implications for food choices and resultant public health outcomes. There are a multitude of studies that indicate that POC and low-income populations have to travel greater distances to access the same resources as white and high-income residents (Blanchard and Matthews 2007; Franco et al. 2008; Coveney and O'Dwyer 2009; Walker et al., 2010; Caspi et al. 2012; Gordon et al. 2011; Shannon 2016). Distance to shops per se was not always the major factor in determining peoples' perceptions of their food access; rather, public transportation access, walkability, price, quality, access to culturally specific foods ${ }^{8}$, safety concerns, and poor customer service were also seen as significant barriers to grocery access (Coveney and O’Dwyer 2009; Shannon 2016). Research further concludes that perceptions of food access have implications for dietary behavior (Coveney and O'Dwyer 2009; Caspi et al. 2012). These findings highlight the fact that food access problems are not confined to areas identified as food deserts, and that the implication of perceived food access can have an impact on health outcomes.

Another key focus of food access research is affordability of available food. Academic research that looks at food affordability typically focuses on the implications that food prices have on where people shop, and how people's shopping behaviors are influenced by factors such as the quality and variety of available food (Latham and

\footnotetext{
${ }^{8}$ In a 2016 study by Shannon, Latino and Hmong participants cited access to culturally specific foods as one reason they would travel to ethnic grocery stores outside their neighborhoods. One participant stated: "Sometimes I'll crave hot sauce or, like, sticky rice or, like, noodles that I can't get at regular American stores. ... There's some Hmong greens that are different, broccoli greens - they don't sell broccoli greens at American stores" (Shannon, 2016, 196). This quote underscores the importance of consumer preference and, in this case, access to foods identified by participants as culturally specific. While ease of access to ethnic grocers is seldom incorporated into food access research, it may offer further insights into customer's shopping behaviors.
} 
Moffat 2007; Zenk et al. 2005). Food prices and availability, particularly for produce, tend to vary more among food retailer type, rather than by geographic location; furthermore, some research suggests that supermarkets tend to offer the highest variety at the lowest price ${ }^{9}$ (Latham and Moffat 2007; Pine and Bennett 2014). Furthermore, positive perceptions of produce selection and quality, rather than price alone, have also been shown to have a positive correlation with produce intake (Zenk et al. 2005). While overall food costs are not always higher in low-income neighborhoods, these findings indicate that increasing access to lower-cost, higher-quality, and higher-variety food vendors in disadvantaged neighborhoods may be an important factor in encouraging produce consumption and improving community health and wellbeing.

In addition to affordability and ease of access, in recent years the public health implications of food access have also emerged as a significant subfield of research. Much of this work points to a positive link between proximity to healthy food resources and increased dietary intake ${ }^{10}$ (Bodor et al. 2007; Abusabha et al. 2011; Michimi and Wimberly 2010; Wang et al. 2007). An abundance of research findings and policy interventions claim that "if you build it, they will come" (Short et al. 2007, 363; Zenk et al. 2005; Blanchard and Matthews 2007), pointing to the link between availability of fresh produce, consumption patterns, and health. Several studies support the notion that supermarket access and obesity are inversely related (Michimi and Wimberly 2010; Chen et al. 2016). In one study, people living in census-tracts identified as food deserts were

\footnotetext{
${ }^{9}$ When comparing the price of goods at grocery stores and convenience stores, one study found a $101.7 \%$ average price increase at convenience stores (Pine and Bennett, 2014, 324).

${ }^{10}$ Interestingly, there is also some evidence that the same if true for unhealthy food; in neighborhoods where unhealthy options increase, residents' consumption of unhealthy foods has been shown to increase, as well (Wang et al., 2007). This indicates that the presence of healthy food options may not be enough to have a positive health impact if an abundance of fast and cheap calories, primarily from fast foods and sugar-laden treats, is also available in the same location.
} 
$30 \%$ more likely to be obese, and $19 \%$ more likely to be overweight than people living in areas not identified as having low food access (Chen et al. 2016).

Interestingly, a number of academic studies also contradict these findings, showing little to no correlation between access to fruit and vegetable and affordability, produce consumption, and health outcomes (Pearson et al. 2005; Lee 2012; Ruopeng and Sturm 2012). Here, influences such as gender, age, and parent's Body Mass Index (BMI) were shown to be the dominant determinates of obesity, rather than price or proximity to food (Pearson et al. 2005; Ruopeng and Sturm 2012). These contradictions demonstrate the need for further research on the health implications of food access ${ }^{11}$.

As this section demonstrates, there are a number of trends that dominate the food access literature. Among these are physical access to stores, affordability, and the public health implications of food access issues. An examination of the research reveals not only significant consensus on the issues among academics, but also considerable disagreement.

\section{Critiques of Research About Food Access}

While academic research on food access is popular in fields such as geography, urban studies, and public health, scholars within those fields have also criticized food access studies heavily. One critique of food access research is that it often frames marketbased solutions to the problem of access. In a retail food market where small retailers are

\footnotetext{
${ }^{11}$ Additionally, at present there is very little food access research that examines the issue through the lens of food safety. A small-scale study of grocery stores in Philadelphia, Pennsylvania found significantly higher levels of potentially dangerous microbes on produce from markets in census tracts where over twenty-five percent of the population lived below the poverty line (Koro et al. 2010). The first of its kind, this work highlights potential income disparities in terms of access to not only healthy and affordable food, but safe food, as well.
} 
increasingly disappearing in the wake of continually consolidating national and transnational corporations, private market solutions are often proposed as the antidote to food injustice issues and price disparities (Agyeman and McEntee 2014). Many measures of food access, such as the premises underlying the mapping of the USDA's Food Access Research Atlas, serve to invalidate the experience of people who may not fit the framework for inadequate food access laid out by academic researchers, or the state (Agyeman and McEntee 2014). Agyeman and McEntee (2014) argue that we need to “...identify and address unequal access to food as well as the corresponding causes, rooted in race and class," (217), rather than simply relying on market-based solutions that do not address the underlying issues.

At present, low-income populations and populations of color are sometimes either blamed for their health problems, or subject to paternalistic campaigns to "educate" them about cooking and healthy eating (Alkon et al. 2013). Health disparities are often framed as a problem with market supply, which supposedly creates unhealthy "obesogenic" environments. In a 2013 study, Alkon et al. assert that supply-side solutions to food access problems, which see food access as primarily an issue of a lack of nearby healthy food options, do not actually account for the foodways of those living within low-access communities. Foodways, which the researchers define as "cultural and social practices that affect food consumption" (Alkon et al. 2013, 127), are complex, and are not merely dependent on what is closest and easiest to access. The authors argue that, contrary to many academic narratives, low-income populations are not simply "takers" of the nearest available food options. The supply-side narrative ignores other possible causes of these problems (such as lack of access to healthcare), and discredits the existing nutritional 
knowledge and provisioning strategies of low-income populations. Furthermore, the researchers argue that, "because the eating habits of low-income people are restricted not so much by geography, but by price" (Alkon et al. 2013, 133), efforts to alleviate these problems should focus on increasing food assistance and wages, rather than relying on market-based solutions, such as adding additional grocery stores to a given neighborhood.

Another critique of food access literature is the vocabulary that researches have imposed upon communities that they label food insecure. While terms like "food desert" and "junk food jungle" may be evocative descriptors, they have also been critiqued for their racialized subtext and bleak imagery (McClintock 2011; Guthman 2008). Guthman writes: "... it is also worth remarking on the language of 'food deserts' which, like the 'dark continent' is itself layered with colonial codings, evoking images of places beyond repair separated from the processes that make them seem so.” $(2008,436)$. Ecological terms like "jungle" and "desert" take on new meaning when applied to landscapes populated by black and brown bodies. These ecological terms are evocative of the primordial and the natural, calling to mind the primitive and untamed. In many cases, this is the exact associative imagery that POC have fought against for years (Riley 2003). ${ }^{12}$

Moreover, the unquestioned logic that some foods are nutritionally "good" or "bad" is built on a shaky, fad-driven foundation of nutritional dogma masquerading as "wisdom" (Pollan 2008). It is not the role of the academy to "damn one group's eating practices[,] nor evangelize about another's" (Guthman 2008, 433). Much of the public

\footnotetext{
${ }^{12}$ For this reason, I have chosen to frame my own research in terms of "food access," which is a broader term that does not have colonialist underpinnings.
} 
health literature runs the risk of imposing the gospel of a particular way of eating upon others, stigmatizing some culinary practices while venerating others.

To summarize, the current academic literature on access to food is a prominent and evolving area of research. In the United States, food-access issues are exacerbated by national and international trends in grocery retailing, transportation inequities, and socioeconomic disparities. However, there is still relatively little consensus about defining terms such as "food access" and "food desert," both within academic research and in public policy. Much of the research currently being done focuses on physical access to food, affordability, and public health implications of food access. However, there is also significant backlash against the current frameworks being used to explore issues of food access. Furthermore, an over-reliance on geospatial data has resulted in a relative lack of qualitative-based work on food access and inequalities, particularly with respect to 'food deserts.'

In the next chapter I provide a snapshot of Lents, the study area of this research. In my description of the study area I touch upon many of the themes that reoccur throughout the academic literature on food access, such as socioeconomic disparities, neighborhood divestment, and walkability and transportation access issues. 


\section{Chapter 3: Study Objectives and Design}

Non-profits, governments, and private businesses have identified Lents as a food

desert, claiming that the neighborhood lacks access to fresh, healthy, and affordable food. Yet, as demonstrated in the preceding chapter, many of the businesses and services within Lents reflect the neighborhood's cultural diversity. For many residents, this may mean having easy access to culturally specific foods that may be difficult to obtain elsewhere. My research explored whether residents perceived neighborhood food access differently from local businesses and non-profits, and I also examined the role that ethnic and specialty markets play in the neighborhood foodscape. I expected to find that:

Hypothesis 1: Although government, business owners, and non-profits working in the area identify Lents as a food desert, not all residents feel that their access to food resources is inadequate.

Hypothesis 2: Culturally specific and specialty grocers in and around the neighborhood are an important, and overlooked, food resource within the neighborhood.

My hypotheses predicted that the business owners and non-profit employees I interviewed would perceive access within the neighborhood as lacking, while residents would have less binary (yes/no) perceptions of their access to food within the neighborhood. Furthermore, I expected to find that ethnic and specialty grocery stores play an important role in the foodscape, particularly for POC. In order to test these hypotheses, I conducted substantive, semi-structured interviews and distributed participant surveys; these were the backbone of my research. I derived additional information from media coverage in local newspapers and academic literature on food access. These methods are described in more depth below. 


\section{Participant Selection and Overview}

I interviewed two groups of participants: businesses owners and nonprofit employees ("Group A"), and community residents (“Group B"). Participants in Group A were recruited via email and via snowball sampling. Business owners and nonprofit employees engaged in food access and food security work were interviewed in order to assess what food access-related work was currently being done in the Lents neighborhood. Five of these interviews were conducted with seven different participants, and these interviews ranged in length from 60 to 150 minutes (Table 3.1). ${ }^{13}$

Table 3.1: Group A interview participants' names, organizational affiliation, and role.

\begin{tabular}{|l|l|}
\hline Participant Name & Organizational Affiliation and Role \\
\hline Nathan Jones & Green Lents, Team Leader of Livable Lents \\
\hline Izzy Armenta & Green Lents, Fellows Team Coordinator for Livable Lents \\
\hline Jen Turner & Oregon Food Bank, Agency Capacity and Education Coordinator \\
\hline Amber Holland & Lents International Farmers Market, Market Manager \\
\hline Ada Hays & SproutUp!, Co-founder \\
\hline Melissa Martin & SproutUp!, Co-founder \\
\hline Brandon Rhodes & Rolling Oasis, Founder \\
\hline
\end{tabular}

Within Group A, representatives of two for-profit businesses that sell produce in Lents were interviewed: Rolling Oasis and SproutUp! Both businesses use language around food access and food justice ${ }^{14}$ in their promotional materials. Rolling Oasis is a bike-powered produce delivery business run by Brandon Rhoades. For $\$ 20$, subscribers receive several types of organic fruits and vegetables, which are delivered to their

\footnotetext{
${ }^{13}$ Notably, two of the participants in Group A-Brandon Rhodes and Nathan Jones—also live in the neighborhood, which allowed them additional insight.

${ }^{14}$ Born out of the environmental justice movement, food justice seeks to "challenge and restructure the dominant food system," with an explicit focus on vulnerable communities and establishing links with other social justice advocates (Gottlieb and Joshi 2013, ix).
} 
doorstep each week. The business" website advertises Rolling Oasis as "ending food deserts one bicycle ride at a time" (Rolling Oasis Grocers 2015). The other business, SproutUp!, currently operates as a weekly produce "pop up" stand in Lents, and the business' cofounders, Melissa Martin and Ada Hayes, hope to eventually open a small market in Lents. Their business focuses on buying overstock and imperfect produce from local farmers, as well as cheap staples, and selling them at a discount in order to prevent food waste, help farmers, and bring fresh foods to low food access neighborhoods.

The other participants in Group A include The Oregon Food Bank, the Portland Farmers Market, and Livable Lents, all of which are non-profits that deal directly with food access in the Lents neighborhood. The Oregon Food Bank is a statewide network of regional food banks with a mission to "end hunger and its root causes" (Jen Turner, Oregon Food Bank). This is accomplished through policy work, education, and food distribution. The Portland Farmers Market is a non-profit that, as of 2016, manages eight farmers markets within the Portland Metropolitan Area, including the Lents International Farmers Market. The market operates every Sunday from 9 AM to 2 PM from June to October, and offers entertainment and activities for children, in addition to local produce. The market currently participates in the Double Up Food Bucks program, which allows participants using SNAP dollars to "match" up to $\$ 10$ of purchases made at the market.

The final organization that was interviewed was Livable Lents, which is a project of its parent organization Green Lents. Founded in 2009, the goal of Green Lents is to build a more sustainable community within the Lents neighborhood. Livable Lents grew out of a "neighbor-to-neighbor community organizing effort in order to survey neighbors, provide that information to developers, and invite neighbors to get involved in local 
opportunities to do something" (Nathan Jones, Livable Lents). In order to accomplish those goals, Livable Lents engages in work around education, transportation, food access, affordability, and other facets of neighborhood "livability." In conjunction with Portland State University, Livable Lents has conducted substantial surveying and outreach in the neighborhood with regard to livability concerns. These findings have been summarized in a 2015 Outreach Report, and a 2016 Community Action Plan.

Participants in Group B were recruited using a combination of social media (including Lents-specific Facebook groups and Craigslist), snowball sampling, and fliers. Fliers were posted around the neighborhood in high-traffic areas, such as bus stops and community message boards at private businesses. The goal of the community member interviews was to assess how residents of Lents perceive their access to food, and to learn more about their shopping and eating habits. Four of these interviews were conducted with a total of five participants, and ranged in length from 27 to 89 minutes.

\section{Interview Protocol}

Prior to conducting interviews, I established a set of leading questions, with different questions targeted toward the two groups (see Appendices B and C). Individual interviews took place throughout the city of Portland at locations specified by the participants. Participants were audio recorded during interviews, and consent for audio recording was obtained prior to beginning the interview. After the interview, participants in Group B were given a survey that was used to collect additional demographic data (see Appendix D. All participants in both groups read and signed the appropriate consent forms prior to beginning the interview. 


\section{Data Analysis}

Interviews were transcribed verbatim from the interview recordings. I verified the accuracy of completed transcriptions by re-listening to the audio-recordings, and correcting any discrepancies. This was also the basis for the first stage of analysis, which involved passive review of the collected data. I then coded interviews manually using a line-by-line analysis of each interview.

In qualitative inquiry, a code is "a word or short phrase that symbolically assigns a summative, salient, essence-capturing, and/or evocative attribute for a portion of language-based or visual data" (Saldana 2009: 14). In my study, the data were coded for patterns, and the first stage of analysis involved creating preliminary codes. In accordance with Braun and Clarke's (2006) methodology for thematic coding, I then reassessed and reordered the preliminary codes in order to develop a set of final codes. These final codes were grouped into categories based on commonalities and emergent themes. During the process, words or phrases were applied to sections of the text in order to identify recurrent topics in the data. The content of these topics was then analyzed separately, in order to capture what were often disparate views on the same theme (Saldana 2009; Tesch 1990). For example, while two participants may discuss their perceptions of a particular grocery store (the "topic"), their opinions on the stores might differ significantly (the "content").

Though many of the same themes occurred across both sets of subjects, I created unique code books for Groups A and B. The participant groups were coded separately (Table 3.2 and 3.3) in order to reflect the different questions that I asked of both groups, and the unique themes that emerged within both interview groups. In addition to thematic 
coding, attribute coding was also used for Group B. This was done in order to shed light on the demographic characteristics of participants, and any relationship to the study's findings (Saldana 2009).

Table 3.2 Group A final code book

\begin{tabular}{|c|c|c|}
\hline Main theme & \multicolumn{2}{|c|}{ Subthemes } \\
\hline \multicolumn{3}{|c|}{ Primary Themes } \\
\hline Food Access & Food security & Barriers to Access \\
\hline \multirow{3}{*}{ Secondary Themes } \\
\hline \multirow{2}{*}{ Infrastructure and space } & $\begin{array}{c}\text { Transportation and } \\
\text { Walkability }\end{array}$ & Neighborhood Geography \\
\hline \multirow{2}{*}{ Equity } & Affordability & Gentrification \\
\cline { 2 - 3 } & \multicolumn{2}{c}{ Retail Space } \\
\hline
\end{tabular}

Table 3.3 Group B final code book

\begin{tabular}{|c|c|c|}
\hline Main theme & \multicolumn{2}{|c|}{ Subthemes } \\
\hline \multicolumn{3}{|c|}{ Primary Themes } \\
\hline Food access & $\begin{array}{c}\text { Specialty and ethnic } \\
\text { grocers }\end{array}$ & Grocery store safety \\
\hline \multicolumn{3}{|c|}{ Secondary Themes } \\
\hline Crime and safety & \multicolumn{2}{|c|}{ Homelessness } \\
\hline \multirow{3}{*}{$\begin{array}{l}\text { Neighborhood } \\
\text { characteristics }\end{array}$} & Diversity & Community \\
\hline & Neighborhood change & Retail \\
\hline & \multicolumn{2}{|c|}{ Transportation and walkability } \\
\hline
\end{tabular}




\section{Chapter 4: Results}

Below, I present my findings from interviews with residents (Group B) and nonprofit employees and business owners working in Lents (Group A). Because a sample size of 12 is relatively small, this research is best viewed as exploratory, and cannot be used to make definitive statements about the foodscape of Lents. However, the findings presented below provide a unique snapshot into current perceptions of food access within the neighborhood.

\section{Group A: Interview Themes}

This section presents the findings from interviews with the five community organizations, described in detail above, whose work relates directly or indirectly to food access in Lents. A number of salient main themes emerged throughout interviews with participants from Group A (Table 3.1). The primary theme was food access, with subthemes of food security and barriers to access. This theme revealed how varied people's perceptions of neighborhood food access and barriers are. Secondary themes include infrastructure and space, with subthemes of transportation and walkability, retail space, and neighborhood geography, and equity, with subthemes of affordability and availability of retail space. The secondary themes focused heavily on perceptions of neighborhood infrastructure and layout, as well as neighborhood change, and the impacts of perceived changes. 


\section{Food Access}

The primary theme that emerged during interviews with Group A was the issue of food access. All of the participants spoke to the food environment of the neighborhood, and what their perceptions of that environment are. The subthemes that emerged were food security and barriers to food access. Interestingly, while many of the participants saw the neighborhood as food insecure, not all of the participants in Group A held the same ideas about the neighborhood's food access.

\section{A. Food Security}

Throughout the interviews all of the participants used language surrounding food access and food security, and several used the term "food desert" to describe Lents. In reference to Green Lents' community outreach efforts, Izzy Armenta remarked that “one recurring theme people mentioned was healthier and more affordable food options." As Brandon Rhodes, a resident and business owner in the neighborhood, also put it: "... so we're in the Lent's neighborhood, it's a food desert, it's food insecure, it's not the most food insecure neighborhood in the neighborhood, but it's historically been recognized as having that issue." Further, part of SproutUp!'s business mission was to operate within a food desert, or food mirage ${ }^{15}$, which is why they chose to situate within Lents.

Although many of the organizations see food access in the neighborhood as a problem, the interviews with participants in Group A also revealed that community organizations within the neighborhood do not all share the same beliefs about food access

\footnotetext{
15 "Part of being a food desert--and that was one of our goals, to go into a low food access [area]. Not necessarily a food desert but maybe they have a New Seasons and nothing else. Um. Or, you know, something like that. They're in a non-desert but technically it really is because the way the access is set up or whatever." -Ada Hayes, Sproutup!
} 
in Lents. Participants had differing opinions about food access and food security; while several participants felt that food access in the neighborhood was insufficient, others saw food access within the neighborhood as a less dire issue. As Amber Holland put it, "I think with what we have to remember with Lents is that it is not a food desert, it's like a step right above that ${ }^{16}$." Jen Turner, from the Oregon Food Bank, also acknowledged that the non-profit actively avoids using the term food desert:

We actively avoid the concept of food desert because it's so fraught a concept. West Hills ${ }^{17}$ is a food desert if you think about it, in the general definition of how food deserts are spatially defined... That's not a sufficient measure when we are looking at the food landscape of a given community, as in the proximity to a grocery store. It really needs to add in other factors in order to understand how people move through space in order to get the food access you need. You can be in a food oasis surrounded by food, and still experience hunger because those resources are not available to you.

\section{B. Barriers to Access}

All of the participants in Group A brought up barriers to accessing food within Lents, including mobility and public transportation access and "other" issues, such as language, price, and, particularly for the Lents International Farmers Market (LIFM), the hours of operation. One of the barriers that participants frequently mentioned was mobility issues and transportation within the neighborhood. This issue was especially prominent in the interview with SproutUp!, currently operating in the parking lot of the Lents Village Apartments which provide low-income housing for people 65 years or

\footnotetext{
${ }^{16}$ While Amber Holland sees food access in the Lents neighborhood as slightly less dire than some of the other participants, the LIFM is still aware of the issues surrounding food access in the neighborhood. The LIFM is actively working to ensure that the market is affordable and accessible: "When we look at a farmers market that is looking to serve a community that is almost a food desert, but not quite, it's important to keep that in mind. I mean, you're talking about food security. It's a big deal. Lents Grocery Buying club is one of our community partners that is going to be there every other week and is filling in the gap with buying in bulk and saving folks a little bit of money to get some of the pantry items that you can't get at the market."

${ }^{17}$ The West Hills is a wealthy neighborhood located west of downtown Portland.
} 
older. The nearest grocery store is more than a mile away and, as a result, grocery shopping is a challenge for many of the residents who struggle with mobility ${ }^{18}$. As Melissa pointed out, even getting to the produce stand can be a challenge: "You can definitely see, you know, it takes a while for them to even get to our stand, and I'm like, oh, dear lord, I can't imagine how hard that must be for you to get on a bus and then go somewhere else and do all that and come back, and then carry it all back." Melissa and Ada also both spoke about the challenges residents have navigating public transportation in order to access groceries:

Melissa Martin: Especially where we're at, there isn't a lot going on. Like, the only other thing people can rely on is the Plaid Pantry, which isn't a lot. And there is a bus that goes right down-

Ada Hays: The 17.

Melissa Martin: The 17 down Holgate, which doesn't seem very useful. But also as you get out there the buses become more scattered, there's not one every four blocks going east west, it's like one every 12 blocks. So that's kind of a problem.

Ada and Melissa were not the only participants that brought up the challenges posed by limited transportation access in the neighborhood. Both participants from Livable Lents also brought up the issue, and Izzy Armenta said it was something that came up frequently during community outreach, stating that many residents wanted access to a more centrally located grocery store that was easier to access via public transportation $^{19}$. According to participants, although efforts are being made to add

\footnotetext{
18 "We have a lot of people who aren't mobile for long distances, they can't carry a lot, you know. A lot of them are getting Meals on Wheels for lunch and would prefer not to, you know?" (Ada Hays)

19 “.... some parts of the neighborhood were frustrated that there's geographically nothing centrally located, so a lot of people were able to drive to places, they weren't concerned. But people who are transit dependent were just, it's either $82 \mathrm{nd}$ or $122 \mathrm{nd}$, those are the two grocery stores that are anchored. So, if
} 
another grocery store to the Lents Town Center, this still fails to address food access in the eastern part of the neighborhood, where the need is most pressing. Nathan addressed this explicitly, saying “personally, I think they're trying to put the grocery store on the west side of the 205, but I really think that continues to miss the need east of the $205 . "$ Brandon Rhodes, who is also a resident of the neighborhood, also expressed frustration with the challenges of biking and taking public transit to the grocery stores in Lents. ${ }^{20}$ Participants also cited a wide variety of other barriers to accessing food in the neighborhood, including: operating times, language barriers, and price. Two participants in Group A cited operating times as a significant barrier for residents, particularly with regards to the LIFM. The neighborhood farmers market operates from June to October, and is only open on Sundays from 9 AM to 2 PM. Izzy stated that, during community outreach, "Another thing I was constantly hearing: people wanted the farmers market around more often. Rather than just Sundays, having a year-round location or having a storefront, maybe because it's more internationally focused, and it's one of the few that actually accepts $\mathrm{SNAP}^{21}$ benefits." Amanda, the market manager, said that she also received frequent feedback about the dates and times; "When you ask [people] when they

\footnotetext{
you're transit dependent, in order to get there for some folks it was location, other folks it was the lack of healthy and affordable options at those stores, too." (Izzy Armenta)

20 "Do you take Trimet? How often do you see in the afternoon the parents with two bags of groceries and they're trying to keep their kid from spilling their milkshake. It's a caricature there, with the kid and the milkshake, but we've all been that person, too, carrying a couple bags. Or, what can I fit in my bike? Like, the basket on front and the bags on back... what can I fit? Well, I found I was buying things that were more shelf stable, and not as poofey as a thing of kale. So I wasn't eating quite as earthily and Michael Pollan as I could.... And I had to leave my neighborhood. It's a mile and a half to get to the Fred Meyer from my neighborhood... just enough to feel like a pain. Just enough..." - Brandon

${ }^{21}$ Supplemental Nutrition Assistance Program (SNAP), also commonly referred to as "food stamps."
} 
want a market they want a market seven days a week and they want it open from 7AM to 7 PM."22

Additionally, two of the participants in Group A also brought up language barriers, and their impact on food access. For Amanda, the market manager at the LIFM, language barriers were one of many elements that deter residents from visiting the LIFM. Everything from "perception of convenience, being welcomed, language barriers, economic barriers, [to] mobility issues" acted as a barrier, since many of Lents' residents simply aren't comfortable going to the farmers market. Ada and Melissa had similar experiences at their produce stand, and during the interview Ada recounted a story about one of their customers, who doesn't speak English:

There's a gentleman who doesn't speak much--I mean, there's a bunch of people who don't speak a whole lot of English. He speaks Russian, and I think he's just not comfortable going into a grocery store to ask questions. He wouldn't. It took him a couple of tries to even communicate with us, we would say hi and kind of do hand symbols and point at things, but he's come back with translations, you know. And it's really cute, but I would really wonder how he would go shopping. And he has a walker, too, on top of that. He has his own physical disability. So it's like, I can't really picture him going anywhere but maybe to a Russian store.

Nearly half of the participants in Group A also expressed complaints with the Fred Meyer at Foster and $82^{\text {nd }}$. One participant referred to it as "filthy" and "the worst thing in the world," and Izzy Armenta said that he has received feedback from community members complaining that this Fred Meyer's prices were higher than those of other stores. Izzy also noted that community members had remarked that there were fewer "natural and organic food options." Nathan also remarked upon the lack of natural

\footnotetext{
22 "So, this concept of 'pop up the market - take down the market' doesn't necessarily work for everybody, and it's not inviting because 'it's one thirty and the market closes in a half hour, I don't have my grocery shopping list together, I don't even know what I'm going to make for this week. I cant go.' That's how I imagine it to be." (Amanda Holland)
} 
and organic products, saying; "they have like half an aisle where at other Fred Meyer's there's like, 4 aisles for organic food or whatever else."

The final barrier that several participants mentioned was price. At the SproutUp! produce stand, Melissa found shoppers were often unsure what their money could buy, those knowledge gaps created hesitation around taking advantage of available resources. Melissa acknowledged that, for many customers, seeing "two dollars for a pound" of peaches isn't helpful. As a result, Melissa often finds herself telling customers something more precise, which makes customers more comfortable; "usually it's four peaches for a pound, just so you know. So it's four for a dollar. We can always jump in there and say that." Amanda also noted that LIFM shoppers were price savvy, and that keeping costs down was a concern. However, she also noted that in the context of the farmers market it was less of an issue "because you're looking directly into the eyes of the person that picked that by hand."

\section{Infrastructure and Space}

The importance of the neighborhood's layout was apparent in many of the interviews, and one of the prominent themes that emerged was the issue of infrastructure and space, with subthemes of transportation and walkability, retail space, and neighborhood geography.

\section{A. Neighborhood Geography}

One of the major consequences of Lents' infrastructure and layout is disparities within the neighborhood in accessing different resources. Because Foster Road and I-205 
are such prominent features in the neighborhood's landscape, and because they act as daunting physical barriers to movement in and around Lents, several participants pointed out that residents in different "sectors" of the neighborhood have access to different resources. As Nathan Jones of Livable Lents stated:

I'd say that Lents is actually broken up into quadrants, and I-205 is a definite north/south divide, but Foster also acts as more or less an east/west one, though it's diagonal; Foster's not straight. There is access to different to different resources, and there isn't access to different resources in each area. So, if you live in the southeast part of Lents, you have a ton of access to green parks, there's the floodplain restoration thing, there's I-205 bike path right next to you, there's spring water bike path.... There's all kind of stuff there, but there isn't a grocery store nearby. There just aren't services, like health services, for anybody anywhere, but then if you live on the west side of the 205, on the south side of it, you're closer to Clackamas Town Center and the resources off Johnson Creek, like Fred Meyer there, or Cartlandia. ${ }^{23}$ Going up to the north side you've got Lents Park and some MAX stops, and Walmart and Eastport Plaza. Most people actually end up going out of the neighborhood for their resources, that's one of the common feedback things we get, too; Lents is great but I have to leave it for whatever I need. It's just where they go for those services, I think, that's different.

Nathan asserts that the neighborhood's quadrants are a major barrier to accessing different resources. Although all residents have access to some services, no one area of the neighborhood is self-sufficient in terms of resource access.

Several other participants also remarked on the neighborhood's fractured feel, including the way the neighborhood's layout and infrastructure impacts daily life. The Interstate highway, in particular, came up frequently. As Ada Hayes of SproutUp! put it, “... you now have a neighborhood split in two... and that's how Lent's feels. That was back in the 70s, and you still really notice that, going from one side of the highway to the other." For people moving around the neighborhood, the highway appears to present a significant barrier. Izzy Armetta, an Americorps volunteer working with Livable Lents,

${ }^{23}$ Cartlandia is a food cart pod located at 8145 SE $82^{\text {nd }}$ Avenue. 
also noted the impact that I-205 has on the neighborhood's connectivity, and its relationship to resource access, referring to the highway as a "huge barrier" that "prevents people from going to other parts [of the neighborhood]. ${ }^{, 24}$

\section{B. Transportation and Walkability}

Like much of Portland, Lents has an abundance of unpaved streets that lack sidewalks; 3.4\% of East Portland's streets are unpaved (City of Portland 2012), and several participants noted that this makes it difficult for residents to get to places such as the grocery store by foot or on bicycle. With regard to sidewalk access and walkability, Ada Hays stated: "And, of course, the lack of sidewalks, too. Those nice people who have walkers, what are they going to do? Walk in the middle of the road to get by the cars?" Participants also noted that walkability issues provide a significant barrier to use of public transportation; while Lents is serviced by the MAX Light Rail and seven different bus lines, getting to and from the bus station or transit center can be challenging, particularly since pedestrians can only cross I-205 at two locations (Bonner et al. 2004).

Even for residents who can get to transportation, many of the buses are seen as inconvenient, particularly for grocery shopping: “... as you get out there [to the East side of Lents] the buses become more scattered, there's not one every four blocks going east west, it's like one every 12 blocks. So that's kind of a problem" (Melissa Martin, SproutUp!). Izzy Armenta also echoed residents' frustration with transportation in the

\footnotetext{
24 "I would also say that 205 acts as a huge barrier, if you're walking, biking, driving. It's just huge traffic rates, the signals are kind of weird, people have issues about that. I think it prevents people from going to other parts [of the neighborhood]. I think more so from the west side to the east side, because there's less resources on the east side, and because people don't want to have to drive under the 205, or bike over there to resources like Zenger [Farm] and Leach [Botanical Garden] and the floodplain, but I think that's a huge deterrent for people to actually go to other parts." -Izzy Armentta
} 
neighborhood, saying; “... some parts of the neighborhood were frustrated that there's geographically nothing centrally located. A lot of people were able to drive to places, [so] they weren't concerned. But people who are transit dependent were just, it's either 82nd or $122 \mathrm{nd}$, those are the two grocery stores that are anchored. So, if you're transit dependent, in order to get there for some folks [the issue] was location."

Several participants mentioned Foster Road, which cuts diagonally through the middle of the neighborhood. A 2004 Planning Workshop Report described crossing Foster Road as pedestrian or cyclist as "difficult and intimidating” (Bonner et al. 2004: 17), and participants in Group A echoed this sentiment. ${ }^{25}$ Although the decision has been controversial, the Portland Bureau of Transportation is currently working with the PDC to address these safety and congestion issues on SE Foster Road by reducing the road from four lanes to two, and adding better pedestrian infrastructure and bike lanes. However, while automobile crash data make the need for a safer transit corridor is clear (Nelson/Nygaard Consulting Associates Inc. 2012), interviews revealed that there are mixed reactions to the proposed changes: "Honestly, Foster is a big problem. Traffic and walkability, I think they're getting a little more help with that and there's that whole new plan with reducing Foster, which is a big fight. It's a whole big fight" (Ada Hays, SproutUp!).

\footnotetext{
25 "...the way that Foster cuts the neighborhood in half, I think people really avoid crossing, so they stick to one side." (Ada Hayes, SproutUp!)
} 


\section{Equity}

Nearly all of the participants in Group A commented on equity issues in the Lents neighborhood, and affordability was at the forefront of these concerns. In addition, retail space affordability and availability was also a prominent subtheme. Many participants mentioned the lack of available space for local businesses, and lamented the high cost of owning and renting a space in Lents.

\section{A. Affordability}

The Lents neighborhood is changing. Once a haven for working class Portlanders, recent increases in the cost of rent and the price of real estate mean that "more and more people are being forced out of their homes (Nathan Jones, Livable Lents)." The median cost of renting a three-bedroom home or apartment in the Lents-Foster neighborhood spiked $16.7 \%$ from 2014 to 2015 , and the average low-income three person family can no longer afford a two or three bedroom house or apartment in the neighborhood (Portland Housing Bureau 2015). Between 2011 and 2014 the Lents-Foster neighborhood also saw the largest increase in median home sale price of any neighborhood in the city, with a 60.7\% average increase in cost (Portland Housing Bureau 2015). Despite the steeply rising cost of living in Lents, the median income for the Lents-Foster neighborhoods actually declined from 2000 to 2013 and, during the same time period, the poverty rate rose from 14\% to $19.3 \%$ (Portland Housing Bureau 2015). While these changes in housing prices and cost of living have brought more people and services to the neighborhood, they have also altered its character. As one participant put it, "Lents is becoming less working class and more middle class as the Portlandification percolates 
out this way" (Brandon Rhodes, Rolling Oasis).

Many of the neighborhood's demographic changes have been attributed to the PDC's decision to mark Lents as an Urban Renewal Area (URA). Although much of the promised infrastructure and development has yet to materialize, the URA designation has heightened neighborhood fears around gentrification and affordability. Anxieties center around fear that the forthcoming neighborhood change is not going to benefit the people currently living there. Instead, there is growing concern that gentrification and the loss of affordability will push residents out of the neighborhood, and farther east. This process has already played out elsewhere in the city on streets like Alberta, in Northeast Portland (Sullivan and Shaw 2011). One participant even likened the changes happening in Lents to those that happened in Northeast Portland: "It's sad to think about what's going to happen in the next five to ten years, where money is gonna go, what's gonna pop up in Lents that the rest of the community won't be able to afford. That's the fear. It's the classic Alberta.... a tourist definition of "nice"' (Melissa Martin, SproutUp!). Amber Holland of the LIFM also noted that there was tension around neighborhood changes, stating; "there's a lot of development and turmoil in Lents right now... turmoil, as in tension within the community in terms of what the development and growth looks like, and who that growth is for."

\section{B. Retail Space}

The anxieties around affordability, gentrification, and neighborhood change have spilled over into the neighborhood's retail sector, as well. Retail space in Lents is at a premium and, in recent years, many businesses and nonprofits in the neighborhood have 
struggled to find affordable locations within the neighborhood. Several participants mentioned this issue, and Nathan Jones stated:

There has been a loss of affordable business storefronts as a lot of the buildings over the last few years have been brought down. If you go out there now, there's a bunch of vacant lots that in 2011 were businesses in old buildings that probably needed to come down anyway, but now that they're down there isn't a place for stuff like that. Which is something we've heard in the economic development discussion, is the need for ma-and-pa affordable storefronts to come back to the neighborhood.

The issue of storefront availability and affordability has had an impact on new and old businesses alike. The "pop-up" produce market SproutUp! has been struggling to find a space in the neighborhood to establish a new produce-centric corner store and community space. Ada Hayes, the pop-up's co-founder, stated that “... just like renting a house, there's availability issues. And the rent for everywhere has gone through the roof, because they're expecting the gentrification." Even established community spaces, such as the Lents International Farmers Market, are experiencing challenges finding locations in the neighborhood. The weekly market's former location in the Lents Town Center was recently slated for redevelopment by the PDC. This forced the market to move a block west to its present location on the corner of 91 st and Foster, and the market will need to move again in 2017, where has yet to be determined. As Amber Holland points out, this process presents huge challenges: "finding a permanent location took me three months, and a lot of my time... without knowing what's happening in the Lents Town Center in the next few years, starting to look at the next location for the farmers market is already a challenge. I have one market under my belt and I'm still unsure where we are going to go! 
That's the thing I struggle with the most. If you pick the wrong location, that can really kill the market."

While one participant expressed gratitude ${ }^{26}$ towards the PDC, several others vocalized their concern that, as with neighborhood's housing market, the changes coming to Lents would not be used to help existing businesses. Brandon Rhodes stated; "we're gonna have a lot of new businesses coming in with PDC filling up every lot around here, and I hope there's room for everyone... There's a lot of people doing a lot of good here, and I hope that they're able to afford to stay. That's probably my biggest fear (Rolling Oasis)." Another participant expressed frustration with PDC's lack of investment in their current property holdings: "It's amazing to me how much property they own [and] let sit unused... they're really just looking to sell it to the next person that's going to throw some apartments up, which is what they did everywhere. And that's the thing. Their name's all over the properties, but they're not doing anything with them" (Ada Hays).

\section{Results: Group B}

This section examines the results of surveys and interviews conducted with five community members living in the Lents neighborhood. Profiles of the results from each individual interview and survey are presented, followed by a discussion section organized by my coded themes. Although the sample size is relatively small, the information below captures some of the diversity of neighborhood perceptions of food access.

\footnotetext{
26 "I wasn't around for the [restructuring of the market locations]. What I can say is that PDC has been an incredible partner. The land that we're on right now is also PDC land. They've responded to everything we've asked for. We've had a great experience with them. I don't have doubts that they have really good intentions and they're putting out an effort. How that plays out and how the community ultimately feels about that is too soon to tell." (Amber Holland, LIFM)
} 


\title{
Group B: Participant Profiles
}

\author{
Jameson $^{27}$
}

Table 4.1 Participant interview and survey overview (Jameson).

\begin{tabular}{|l|l|}
\hline Age & 44 \\
\hline Gender & Male \\
\hline Ethnicity & Black/African American \\
\hline Highest level of education completed & Some college \\
\hline Annual household income bracket & $\$ 35,000-49,000$ \\
\hline Location in neighborhood & Northeast quarter \\
\hline Rent/Own current home? & Own \\
\hline People in household & 3 \\
\hline Current household residents & Couple with kids \\
\hline SNAP recipient? & No \\
\hline Community or home garden? & Home garden \\
\hline
\end{tabular}

Jameson, who is Haitian, and his wife, who is Japanese, currently live with their six-year-old son in the Northeast section of Lents. They moved from Japan to Portland six years ago, and purchased their home in Lents in 2015. The family moved to Lents because it is an "upcoming neighborhood, and also from what we're looking for it met our price bracket. And also we like Southeast because Southeast has a lot of flavor. It's rough, but [laughs] it's not boring...” The family values cooking, eating meals, and shopping together, and they also have a large garden in their backyard, which they use to grow food and teach their son; "I think it is important for our son to understand [where food comes from], and also appreciate it."

For the family, a big draw of their current location is the neighborhood amenities, and their son is a big factor in their living considerations. Jameson stated, "we picked this particular house because we are surrounded by two parks, because we have a son; that's why we're living here." Jameson also spoke highly of the neighborhood's transportation

${ }^{27}$ All of the resident names are pseudonyms. 
access, which he described as "very convenient. ${ }^{28, "}$ While his wife is able to drive their car, Jameson is not; as such, the family depends on a car, bike, and public transportation in order to get around their neighborhood and run errands.

Another positive aspect of the neighborhood is the sense of community, which Jameson described as "really good. ${ }^{29 "}$ Jameson also describes the neighborhood's linguistic and cultural diversity as an important draw for he and his wife; "There is a small Eastern European population that I've noticed, even on this block. Because, you know, you can hear the different languages, and so it's kind of nice to hear Chinese Mandarin, Cantonese, you know, Slovenian, Afrikaans, so it's really nice when you have the windows open." Jameson also described how important it was that his son gets exposed to different cultures. Jameson's son currently attends Richmond Elementary School, which is a Japanese Immersion school, and Jameson described the school's cultural focus as "one dimensional," and expressed how important it was to him that living in Lents exposes his son to different cultures and ideas. ${ }^{30}$

For Jameson and his family, one of the other major benefits of the neighborhood is its proximity to their preferred grocery stores, and culturally specific products. During the interview, Jameson stated that, in terms of convenience and location, "I feel like

\footnotetext{
28 "But transportation is very convenient, because the bus station is right there and also the Max is probably seven minutes walk. So, to go anywhere, whether downtown or different parts of PDX, is very easy, very convenient. And biking is really good."

29 "The people are really good. The people are really friendly and very supportive of me. In Lents there's a really good sense of community. So, that I really like. Not only physically here in the neighborhood, but also online. Because online there are different [Facebook] groups for Lents folks. And, so that... I get a lot of information from them through [Facebook]. So, that's been really, really helpful."

30 "I mean, especially with our son, for him to be exposed to [diversity] is very important. And his school, it's not very diverse. He goes to Richmond Elementary school, it's a Japanese immersion program, so from my point of view it's one dimensional. But it's a wonderful school, the people are great, so he can improve his Japanese. But in terms of being exposed to different ethnicities, in his school he doesn't have that opportunity. Whereas here he has that, in Lents. So, that's a good balance and that's very important."
} 
there's no other place where I can get the stuff that we need for my family." When the family first moved to the neighborhood, the closest supermarket was the Safeway on $122^{\text {nd }}$ Ave, and, in terms of quality and price, it was "not one of our favorites." WinCo recently opened outside of the Lents neighborhood, and the opening was a big event for the family:

The supermarket that we like is WinCo, and so WinCo just opened on $82^{\text {nd }}$ and Powell. When you have a family, strange things make you happy [laughs]. So when we learned that WinCo was opening here we got so excited, oh! We were counting down until it was supposed to open [laughs]! So, finally it opened, so we go there very often and it's one of our favorite supermarkets because it provides what we need and it's very cheap, and the quality of the food is pretty good.

During the interview Jameson mentioned that the WinCo near Lents offers cheap prices, quality, and the products that they want. As he put it, "whatever we need, we can find there." Jameson also expressed his satisfaction with the international section and the wine selection, and he said that it was also one of the only places they could find cherry tomatoes, which their son loves ${ }^{31}$. Jameson also values living close to Fubon, a large Asian market located on SE $82^{\text {nd }}$ Ave, a few blocks north of Lents. The market is a good resource for Jameson and his wife, since it offers specific products, such as Japanese rice, coconut water, and coconut cream, for "very cheap."

Jameson also repeatedly brought up the fact that living in Lents gives his family convenient access to foods they might not find elsewhere in the city; "So, for convenience, from my point of view, I feel like there's no other place where I can get the

\footnotetext{
31 "So, that in itself is very unique to WiCco. That particular tomato. But other than that, the friendliness that they provide. I hate to say this, but it's not a forced friendliness, it's very natural, and it makes us very comfortable there. But, the food is very reasonable in terms of price. And whatever we need we can find there. I like wine, I get my wines from there. And they do have an international section; you can find stuff there. It's like a commercial, but I really like WinCo! WinCo is the place to go..."
} 
stuff that we need for my family." During the interview, Jameson also relayed a story about a particular soda he grew up drinking in Haiti, and how surprised he was when he saw it for sale in the neighborhood:

... being that I'm Haitian, and my wife is Japanese, we can get a wide variety of food in this neighborhood, whether we go to WinCo or Fubon... In Haiti we drank a particular soda, it's a fruit soda and so when I went to Fubon and I went into the juice area I was very surprised to see [laughs] that particular soda there. I was like, "whoa, I don't have to go anywhere! I'm home!" [laughs] So, I think the grocers or the supermarket owners are very sensitive of folks that are living in their neighborhood.

When asked if he felt that distance to food stores was a barrier to grocery shopping Jameson responded that, while the neighborhood may have had a problem in the past, he no longer saw distance as a barrier to food access in Lents. With the opening of new grocery options on the periphery, Jameson now sees Lents as "a food village,"32 capable of supporting neighborhood residents with diverse, cost-saving options.

While Jameson was almost unrelentingly positive about the neighborhood, he also brought up the challenges Lents has been having with its homeless population and, more specifically, the crime that has comes with it: "It's not so much that there are many homeless visible. The problem is the behavior that comes with it. And even in this neighborhood, I saw needles in the park." While this wasn't an issue for the family, Jameson also brought up the lack of non-food retail options, noting that "in terms of shopping for clothes or something, you're not going to find that here. That doesn't exist. But you know, people who live here don't really care for that, you go somewhere else."

\footnotetext{
32 "Again, if you have a family, to be in the Lents neighborhood you have options. You can go to WinCo, you can go to Fubon, and the prices are wonderful. Unlike, you know, other areas. And also, not too far there's the Grocery Outlet... So Lents really is becoming a food village, the way I see it going."
} 
Amanda

Table 4.2 Participant interview and survey overview (Amanda).

\begin{tabular}{|l|l|}
\hline Age & 38 \\
\hline Gender & Female \\
\hline Ethnicity & White/Caucasian \\
\hline Highest level of education completed & Trade School or Associates Degree \\
\hline Annual household income bracket & $\$ 75,000-\$ 99,000$ \\
\hline Location in neighborhood & Northwest Quadrant \\
\hline Rent/Own current home? & Own \\
\hline People in household & 2 \\
\hline Current household residents & Couple without kids \\
\hline SNAP recipient? & No \\
\hline Community or home garden? & No \\
\hline
\end{tabular}

Amanda has lived in Portland for the past sixteen years, and she bought a house in Lents thirteen years ago. She and her husband both work in the food industry, and they spend a lot of their free time "working on the house," which Amanda described as a "fixer-upper" in the neighborhood's northwest quadrant. The couple likes the diversity that the neighborhood offers, as well as the "relaxed feel" and inviting neighborhood community. ${ }^{33}$ They also have family in the neighborhood; Amanda's husband went to high school in Lents, and his father and stepmother still live in Lents.

One of Amanda's complaints about the neighborhood is its walkability. During the interview Amanda stated that she doesn't "really walk around the neighborhood a lot" because "the street I live on doesn't have sidewalks," which she described as a challenge

\footnotetext{
33 "I think it's incredibly diverse. I use the word gritty, when I'm talking to my friends who live in other neighborhoods. I like the grit, though. I like that it's not cookie cutter. I like it that my husband and I joke that we appreciate the fact that our front lawn is less then desirable, but we don't have to water and do weed killer and manicure, we don't have to worry about neighbors complaining [laughs].... you can be a lot more relaxed about things like that. We like the neighborhood. The people are awesome. Everyone we run into, all the neighbors are great."
} 
for neighbors with strollers or walkers. ${ }^{34}$ Amanda felt that the neighborhood has a "lot of opportunity for sidewalks," and for further infrastructure investment by the city. While

Amanda was hopeful about future improvements, she also expressed frustration with how slow the PDC's efforts in Lents have been, and how little retail the neighborhood has;

We moved to Lents because of the PDC, that commission. That bond or whatever that they've been investing in, is like hundreds of million of dollars they've been investing in the neighborhood. We moved there because we knew that was in place and we were like, great, it's going to be improving. That was like, 13 years ago, and we have seen improvements, but you would think that with the amount of money and with the amount of time that it would be a completely different neighborhood now. But I'm still hopeful for the future; I know they're going to be doing street improvements on Foster, I think that will help bring more local businesses in investing in storefronts. There's a lot of empty retail space. I wish that the city would do something about foreclosed and abandoned homes. That's a problem. I would really like to have more businesses that I want to support locally.

Amanda also mentioned that she and her husband struggle with safety and crime in the neighborhood, particularly as it relates to the neighborhood's recent surge in its homeless population. Amanda is involved in Lents' Neighborhood Watch, which has been working to combat the "illegal activity" associated with homelessness, including drug use, drug sales, prostitution, and illegal dumping. ${ }^{35}$ Amanda and her husband are "really cautious of crime," which she described as extremely prevalent in the

\footnotetext{
34 "The neighborhood, there's a lot of things the neighborhood doesn't have, you know. I don't really like, walk around in the neighborhood a lot. The street I live on doesn't have sidewalks, it does have speed bumps, thankfully... there's a bus line, the number ten runs on my road. So, there's people, you know, pushing shopping carts and there's people in wheelchairs and walkers, and there's people with strollers. And they're in the road, because there's only gravel... I feel awful when I see someone with a walker pushing up and down the street."

35 "I'm really involved in Neighborhood Watch that's happening right now with a lot of homelessness. It's not necessarily--homelessness gets misinterpreted. For the group and the neighbors that I'm involved with, it's really about illegal activity. Most of it is drug use and drug sales, illegal of course. And prostitution. Just a lot of undesirable activity that goes along with it. Illegally parked RV's and trailers that are dumping their wastewater in out alleyways, and just on the side of the street in the gutter.... It's not livable, to have urine being dumped on your street..."
} 
neighborhood, stating; "Nothing is safe [laughs]; even if it's locked down it's not safe." Amanda and her husband also live behind an abandoned house where homeless camp, and she worries about her husband's safety when he is in the yard alone at night.

In terms of grocery access, Amanda typically does her shopping via car, and she usually shops at the Fred Meyer on $82^{\text {nd }}$ and Foster, since it's about a mile from her house and it's "really convenient" when she's coming home from work. She also values her familiarly with the store, saying "I know the layout of the store so I can get in and do my shopping really fast." She and her husband also shop at Fubon and Oriental Food Market, where they are able to get specialty products like seaweed salad, and hot sauces, which Amanda described as being "a lot cheaper to buy there than it is at Fred Meyer, like half the price..." For Amanda, the food stores around Lents offer her "access to what I want." When asked if she feels that she has adequate access to food retail locations, Amanda responded;

Well, I mean, Lents is a huge neighborhood, and I'm on $89^{\text {th }}$. I'm really close to that Fred Meyer. So, for me and my surrounding neighbors, yes. I think we do. We have the farmers market on Sunday, which is also right in that area. And then we have the multiple Asian markets, and we have the Fred Meyer. So, in that area it's good, but if I was on the other side of Lents I don't know how they would feel. I would imagine they would have a harder time. 
Table 4.3 Participant interview and survey overview (Ali).

\begin{tabular}{|l|l|}
\hline Age & 32 \\
\hline Gender & Male \\
\hline Ethnicity & Black/African American, Asian/Asian \\
& American, Native Hawaiian/Pacific Islander, \\
& Native American/Alaskan Native, \\
& White/Caucasian, Persian, Turkish \\
\hline Highest level of education completed & Bachelor's Degree \\
\hline Annual household income bracket & $\$ 50,000-74,999$ \\
\hline Location in neighborhood & Southwest Quarter \\
\hline Rent/Own current home? & Own \\
\hline People in household & 1 \\
\hline Current household residents & Single adult without kids \\
\hline SNAP recipient? & No \\
\hline Community or home garden? & No \\
\hline
\end{tabular}

Ali is a full time primary care worker and graduate student who has lived in Portland for fourteen years. Originally from the Salt Lake City area, he identified himself to me as "single, homeowner, multiracial." Ali purchased a house in the Lents neighborhood a year and a half ago, and recently began to get more involved in the neighborhood. For Ali, a big draw of Lents was the diversity;

I really like the fact that the demographics of our neighborhood are a lot more diverse than Portland in general. Coming from a multi-racial background, I really have a hard time with the monoculture that in Portland. So, it's really nice to be in a neighborhood that's $60 \%$ Caucasian, $15 \%$ Latino, 15\% Asian, 7\% African American... So, to me, that's how I live and that's what I really enjoy. So, that's what I like about Lents; it's part of the reason I moved in to Lents. I don't mind a poorer neighborhood, more rough neighborhood.

Ali either walks or drives to do his weekly grocery shopping, which is often done at the Fred Meyer on Johnson Creek Boulevard, or the Trader Joes outside of the neighborhood. However, the majority of his shopping is done at Asian grocery stores, including Fubon, and Ali acknowledged, "I would probably say I spend more time in 
ethnic stores than I do in American stores." Ali stated that its proximity to more culturally diverse grocers is important to him, saying: "coming up from a multi-racial background, that's really important. Because I identify more with those people than I do with, like, if I go into the Pearl...".

While Ali values having access to stores like Fubon, he also said that in Lents it was still difficult for him to access some the foods associated with his culture, since "Persian, Turkish, Kurdish... It's not necessarily in this neighborhood." For Ali, it can be hard to find some of the spices and cooking supplies that are specific to Middle Eastern cooking, noting:

Good Middle Eastern food for me is not in the neighborhood. The spices, they have some unique spices, they don't have them there. When you go to a Middle Eastern store you get your skewers and you get the charcoals and the things that are very like, around that culture. They just don't have that in the neighborhood.

Ali attributed the lack of Middle Eastern specific foods to the fact that Lents is predominantly Caucasian, Latino and Asian, ${ }^{36}$ As a result, he has to travel elsewhere in the city to access specific foods, such as halal meat. ${ }^{37}$

While Ali did not say that he, personally, had difficulty accessing food, he saw food access as an issue for others in the neighborhood. He felt that fresh food was especially lacking, stating, "the fresh food isn't really there. You have Fred Meyer on both ends of Lents, but from a cost perspective for the working class neighborhood that it is, is there really access?" In addition he saw health literacy, time, convenience, and

\footnotetext{
36 "I can't find a lot of things I'm usually looking for, you know, and so it's hard to find it in the neighborhood. A lot of my culture, they're in Beaverton, they're on Barber, they're spread out in different areas... Persian, Turkish, Kurdish... It's not necessarily in this neighborhood... This neighborhood is predominantly Latino and Asian, so it's expected to have that. I'm not a huge fan of all the fried Latino foods, so I tend to go to all of the Asian joints."

37 "I usually go to like halal for my meat, halal markets. But they don't have them [in Lents]. Like, there's this one in Beaverton..."
} 
walkability as food access barriers within Lents, stating: "our sidewalks are shit!"

Furthermore, while he didn't feel that distance to stores was a barrier for accessing food "inside of 205," he felt that distance to grocery stores was a problem elsewhere in the neighborhood.

For Ali, one of the drawbacks of the neighborhood is the fact that "there's not really much community building., ${ }^{38}$ Ali saw many of the neighborhood organizations as stifling, stating "in our neighborhood there are a lot of people that have very loud voices, and from a social worker lens use their privilege and status to really stifle people, make people not want to come out and participate." Another big drawback of the neighborhood is its reputation. Ali mentioned that Lents was once known as "felony flats," and that it's still "the armpit of Portland." However, Ali also voiced concern over the rising cost of living in the area, stating that the value of his house has risen $20.7 \%$ in a year and a half, and "that's a problem." 39

\footnotetext{
38 "There's not a really strong sense of [community]. Like, there's not a big community center, like the one that's in the William's neighborhood that all the white people go to... That's the truth of the neighborhood." 39 "I make more than the average family of four, like, how many people are getting fucked right now that just want to have a place? And Lents is like, the pinnacle of that neighborhood that in 15 years is gonna be a completely different place... This neighborhood is gonna change."
} 


\section{Emily}

Table 4.4 Participant interview and survey overview (Emily).

\begin{tabular}{|l|l|}
\hline Age & 34 \\
\hline Gender & Female \\
\hline Ethnicity & White/Caucasian \\
\hline Highest level of education completed & Some college \\
\hline Annual household income bracket & $\$ 35,000-49,999$ \\
\hline Location in neighborhood & Northeast Quadrant \\
\hline Rent/Own current home? & Own \\
\hline People in household & 2 \\
\hline Current household residents & Couple without kids \\
\hline SNAP recipient? & No \\
\hline Community or home garden? & No \\
\hline
\end{tabular}

Emily grew up in Portland, and has lived in Lents for the past seven years. She bought a house in Lents because it was affordable, it has good transportation access, and it is close to her family. ${ }^{40}$ When asked to describe Lents, she stated: "I like to think of it as up and coming because I like to give it a positive spin. It is a good neighborhood but it feels like we are forgotten and neglected." Emily expressed frustration over how long it took the city to begin addressing Lents' homeless population, and how long it has taken for the PDC's efforts in the neighborhood to bear fruit. ${ }^{41}$ While she enjoys neighborhood amenities such as easy access to biking trails and the neighborhood's baseball team, the Pickles, she doesn't like “the reputation that people give Lents, that it doesn't deserve... it used to be called 'Felony Flats.' I don't like when people say that. I mean, we're part of the city too, and sometimes it feels like we're not." Emily also expressed a desire for

\footnotetext{
40 "You can get anywhere quickly, whether that's public transit or car or bike just because of all the options. Personally, it's close to all my family and friends. It was affordable... it is affordable. At the time that's why I bought a house here. I didn't have a lot of other options."

41 "Well, I'm sure you're aware of this - the situation on the Springwater Corridor. I bike that, run it everyday for 7 years. And it's been an increasing problem for two years; I can pinpoint it to when it happened. It's like nothing happened from the city the county, whatever. Just things like that. It just feels like it takes a long time for action to happen here. The PDC is doing a lot of development in the town center here. Like I said, I've lived here for seven years and I waited 5 years for anything to happen. It's just very slow."
} 
more retail options in the neighborhood, stating, "I don't have a reason to come to downtown Lents unless I'm hungry.”

Emily and her boyfriend typically shop at the Portland Fruit Market for produce, and the Johnson Creek Fred Meyer. When asked why she chooses to shop at the Johnson Creek location, Emily said:

I don't really like the Foster Fred Meyer... I've heard lots of things, and the shoppers are oftentimes not people you want to be shopping with. I got threatened for looking at a woman's boyfriend one time, even though I was not looking at him. And then, a bomb went off a couple months ago. Someone detonated a bomb in the toiletries aisle... I've heard people fighting in there. And I think that store is just neglected. I've seen the Johnson Creek Fred Meyer get renovated and remodeled. I've seen other stores get remodeled, and that one doesn't.

Emily prefers shopping at the Portland Fruit Market because the quality is better than Fred Meyer, and “it's inexpensive, and they're super friendly, and they seem to have more local items than Fred Meyer." She and her boyfriend also visit the farmers market each Sunday, but they do they bulk of their shopping at the fruit market because it's "cheaper."

When asked if she felt that she had any barriers to shopping for groceries as often or at the locations she prefers, Emily lamented that there was no convenient store from which to get basic ingredients while cooking, which she does frequently;

... it's hard to go if you are cooking something and then you're like, 'oh man, I'm out of salt.' There's no convenient run-down-the-block to get salt. So, I actually live a mile from Foster Fred Meyer, which isn't far, but it's definitely not close enough to walk just to get salt or even if you are getting more than just a few things. I mean, who can haul the groceries back? So, I do wish that there was maybe a small or closer market where you can be like, 'oops, I forgot something, and I need something really quick and convenient' where you can just run down and get it.

42 “... they [the Portland Fruit Market] have a sign that was, like, "Peaches - 88 cents a pound," and I was like, "I just paid $\$ 3.50$ at the farmer's market. We're going [to the fruit market] now." 
While Emily does live close to three convenience stores, she stated that cost and product selection at those stores was an issue for her. ${ }^{43}$ When asked if she felt her community had adequate food access, Emily stated that she felt the lack of convenient grocery stores in her part of the neighborhood was a problem for her and her neighbors. She also stated a desire for a "small market" like Green Zebra, ${ }^{44}$ since "Lents does already have a lot of big stores like Fred Meyer, Walmart, WinCo." When asked if distance to grocery stores was an issue in her neighborhood Emily stated that she thought it was, and she mentioned that she thought she lived in a "food desert." 45

\section{Geoff}

Table 4.5 Participant interview and survey overview (Geoff).

\begin{tabular}{|l|l|}
\hline Age & 44 \\
\hline Gender & Male \\
\hline Ethnicity & White/Caucasian (German American) \\
\hline Highest level of education completed & Trade School or Associates Degree \\
\hline Annual household income bracket & $\$ 35,000-49,999$ \\
\hline Location in neighborhood & Not stated \\
\hline Rent/Own current home? & Own \\
\hline People in household & 5 \\
\hline Current household residents & Married with 3 children \\
\hline SNAP recipient? & No \\
\hline Community or home garden? & Home garden \\
\hline
\end{tabular}

Geoff moved to Portland from Dallas, Texas 24 years ago. He and his partner have three children, one of which successfully battled leukemia several years ago, which

\footnotetext{
43 “It's either a Plaid [Pantry] or a 7-11. And there's two local ones, but they're more expensive than a 7-11. And they still are just serving beer, chips, soda, etc."

${ }^{44}$ Green Zebra is a local chain of small "corner" grocers that carry a full range of produce.

45 "I've heard stories from other neighborhoods about being in a food desert, which I think I am. I think a definition is like a mile or something. Of other people just having to take public transit for miles and miles to get a good deal or the food they want, so, yeah."
} 
has had a lasting impact on his family's life, and the way they eat. Geoff and his family settled in Lents because he has "a ton of family in the area," and his grandmother once owned the house they now live in. For Geoff, the neighborhood's cultural diversity is "an amazing element of what I like." He also values the access that Lents offers to "the city, and forest, and everything," and he appreciates that there are neighborhood parks.

However, he noted that they are a "mixed blessing" because they are "horribly managed." Geoff takes his children outside of the neighborhood to go to the park because "It's poorly maintained, doesn't have the features of a decent park, and it's poorly patrolled. So, there's a criminal element present."

Geoff felt that "accessing government and volunteer opportunity" was a challenge in the neighborhood, and that access was not open to everyone. ${ }^{46}$ He also lamented the neighborhood's lack of general resources, saying, "We don't have a library, we don't have a decent amount of general resources, community resources. There's no good large-scale employer present in the community and there's enough land that there could be." He expressed frustration about the fact that "there's no gathering spaces of any substance" in the neighborhood, and that there is a lack of community engagement. ${ }^{47}$

Geoff does his shopping at many of the different grocery stores in and around the neighborhood, and he usually walks or drives to the grocery store. When asked where he and his family typically shop, he responded;

\footnotetext{
46 “... you have this very minority white population, and I mean minority not in the sense that they're outnumbered, but I meant that 'they're the only active 40 people [involved in neighborhood issues]', right? And they presume to steer and dictate the things happening in Lents. It's horrible. It's a horrible misrepresentation of a huge diverse community."

47 "There's a lot of land owners. There are some very wealthy folks, but they are completely disengaged from the neighborhood."
} 
Sometimes - very rarely - Walmart. I hate Walmart. Recently they opened WinCo. I love WinCo. I just like the way they present their product. It's super cool.... And then Freddy's. Freddy's is kind of the closest option for me, and the thing I hate about Freddy's is, like, there's such a shitty customer service present in the store. There's such shitty loss prevention present in the store. I watch people walk out with grocery carts full of food, numerous times. I can't even count them any more. They hassle you in the parking lot... And I do sometimes go to Trader Joes. The problem with Trader Joes is you can't just walk in and shop for a family and not burn your fucking wallet up.

During the interview Geoff repeatedly brought up the negative experiences he had had shopping at the Fred Meyer on $82^{\text {nd }}$, including theft and violence. ${ }^{48}$ These safety concerns play a large role in Geoff's grocery shopping choices, since he often has his children with him when he shops. ${ }^{49}$

Geoff also frequents a number of ethnic grocers just outside of the neighborhood, including a German meat shop, a Russian grocer, and some of the Asian stores. He expressed interest in the neighborhood getting "a good meat counter," and expressed frustration with the fact that an affordable grocery option hasn't been brought to the Lents Town Center, stating; "[we're] a working neighborhood that doesn't have time to be fucking around begging for a chain to come in and make their needs known." He also saw walkability as a huge barrier to accessing food and other resources in the neighborhood, saying, "We're a car community, really... our community [has] really been designed around cars. Everything you see is a reflection of that."

\footnotetext{
48 “I've seen crazy shit... I've talked to the manager, and I've talked to loss prevention. They don't give a fuck. The manager said they were gonna have one of the first armed security guards in this area. There are only three stores that are gonna do it and we're gonna have it here. And I'm like, that's cool, but you have a fucking armed guard at the grocery store."

49 "I think that there is a real element of safety for me having kids. I don't like taking my kids to Walmart or Fred Meyer because it's just not safe for them... For me, as a parent, I don't want me kids going there and watching people fight at the can return. It's ridiculous... So, access to the stores in a safe and friendly fashion.... So, that's a barrier to me. Is it safe to take my kids? Safety. Which is so fucked off to say about a grocery store; is it safe to take my kids in there?"
} 
In addition, Geoff felt that distance from food stores was a significant problem for some members of the neighborhood, particularly people living on the east side of the neighborhood; "If you're out at $111^{\text {th }}$, you're kind of far from everywhere else." He noted that the southeast section of the neighborhood is especially lacking in grocery store options, saying "it's a bit of a [food] desert" while also acknowledging that people on the "perimeter" of the neighborhood tend to have easier access to grocery stores.

In addition to buying food from the grocery store, Geoff and his family have an extensive home garden in which he grows a wide variety of food crops. His grandmother also used to work in the yard, and he has carried on that tradition. While Geoff expressed some interest in the neighborhood's community garden, he was also skeptical of the experience of communal gardening, particularly in Lents. While he did not specify who, he was emphatic that in "Lents, they've destroyed it. They've destroyed the community garden. They invade it and they steal everything and all your energy has gone to shit." He

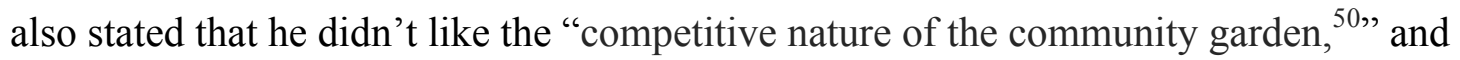
that the registration process was a barrier to his participation.

\section{Group B: Interview Themes}

The interviews with Group B revealed a number of salient main themes (Table 3.3). As with Group A, several of the themes that were brought up repeatedly by participants were not directly tied to food access in the neighborhood. Themes that did not conform to the main focus of the research were coded as "secondary themes," and are

\footnotetext{
50 "I don't know that I'm comfortable in that communal space trying to garden, cause you know, you'll have that fucking old lady, who's like, "ha ha! Look at these huge cucumbers! Fuck you and your little gerkins!" And you're like, fucking bitch! So, I don't like the competitive nature of the community garden. Like, watch me fail, thanks. Right?"
} 
included despite the fact that they may or may not have a bearing on food access within the neighborhood. Many of these secondary themes have important implications for neighborhood livability, and thus help to paint a picture of Lents as a whole, and not merely as a space in which grocery shopping and eating occurs.

The dominant primary theme that emerged was food access, with subthemes of grocery store safety, specialty and ethnic grocers, and culturally specific products. The dominant secondary themes were neighborhood characteristics, and crime and safety. The main theme of neighborhood characteristics had a number of subthemes, including; diversity, community, neighborhood change, retail, and transportation and walkability. Within the main theme of crime and safety, homelessness surfaced as a distinct subtheme.

\section{Food Access}

Food access was the dominant theme of the interviews with Group B, and during coding two distinct subthemes emerged; grocery store safety, and specialty and ethnic grocers.

\section{A. Grocery Store Safety}

Two of the five participants brought up the issue of safety while shopping for groceries. In the case of grocery shopping safety, participants specifically referenced their experiences shopping at the Fred Meyer grocery store on $82^{\text {nd }}$ Avenue. Both participants (Emily and Geoff) had negative perceptions of the grocery store's safety. In her interview, Emily cited safety concerns around a bomb that was set off in one of the 
aisles $^{51}$, as well as negative interactions with other customers at the store. On the other hand, Geoff expressed his concern about taking his children to the store, citing widespread theft within the store and violence at the can return.

\section{B. Specialty and Ethnic Grocers}

When asked about their grocery shopping habits, all of the participants mentioned shopping at specialty and ethnic grocers in or around the Lents neighborhood, and the vast majority of participants (4/5) mentioned shopping at culturally specific grocers there. Ali said that he spends most of his time shopping at culturally specific grocers in the neighborhood, and that he favors the Asian grocers, including Fubon. When asked why he chooses to shop at those locations he stated, "I identify more with those people." Here, Ali contrasted cheaper and more culturally diverse stores with whiter and more affluent retail locations in Portland. During the interview, Geoff said that he shops at a Russian grocer and a German meat shop near the neighborhood, as well as one of the Asian grocers in Lents.

Emily stated that she regularly shops at the Portland Fruit Market ${ }^{52}$ in the neighborhood because it's "inexpensive," "friendly," and has a higher selection of local products than Fred Meyer. She and her husband also frequent the farmers market in the neighborhood. Amanda had similar reasons for doing some of her shopping at Fubon and Oriental Food Value, which are both Asian grocers in the neighborhood. She stated that those locations carried goods she couldn't get elsewhere (such as hot sauce and seaweed

\footnotetext{
${ }^{51}$ One May $21^{\text {st }}, 2016$ a small explosive was set off at the Fred Meyer on $82^{\text {nd }}$ Ave.

52 The Portland Fruit Market is a specialty grocer that sells mainly produce, as well as select specialty products such as beer and kombucha.
} 
salad), and that the prices were significantly less than Fred Meyer's. Jameson also mentioned shopping at Fubon, and he also cited price as one of the reasons that his family chooses to shop at that location. In addition, however, Jameson cited the availability of culturally specific products as a big draw of the location for him and his family.

\section{Crime and Safety}

The issue of neighborhood crime and safety was brought up by four of the five participants. For many of the participants, the issue of crime and safety was raised in the context of the neighborhood's recent surge in its homeless population, and four of the five participants mentioned concerns regarding crime and safety issues associated with homelessness in the neighborhood.

For several of the participants, homelessness itself was not the issue, per se. Jameson stated that the behaviors and crime that he perceived as being associated with homelessness were the main problem in Lents. During the interview he stated that, "even in this neighborhood, I saw needles in the park," expressing concern over drug use in the neighborhood's public spaces. Amanda also echoed a similar sentiment, saying that the issue of homelessness in the neighborhood was "really about illegal activity," and not homelessness itself. Amanda also brought up the presence of drug use and drug sales, and she also mentioned the presence of drug paraphernalia in the neighborhood, stating that she often saw the "caps that are on the hypodermic needles that people use to shoot up with" discarded in the empty lot behind her house. Emily and Geoff also brought up 
homelessness in the neighborhood, and they both indicated frustration with the lack of consistent enforcement ${ }^{53}$ and timely response by the city of Portland.

\section{Neighborhood Characteristics}

Throughout the interviews with Group B, many participants brought up issues that could be described as neighborhood characteristics. A number of these subthemes have a direct impact on food access within the neighborhood, while others speak to participants' general concerns about Lents. The subthemes are described below.

\section{A. Transportation and Walkability}

During the interviews, all of the participants in Group B spoke about transportation and walkability within Lents. Four of the participants spoke negatively about walkability issues within the neighborhood, with two participants specifically citing poor sidewalk infrastructure as a barrier to walking. However, two participants also spoke highly of the convenient bus and light rail access, citing that as a positive feature of living in Lents.

\section{B. Diversity}

Four out of the five participants mentioned the ethnic and cultural diversity of Lents as a feature that they value in the neighborhood. Out of these four participants, the two that identified themselves as white/Caucasian mentioned in passing the value of the neighborhood's diversity in passing. For the two participants, however, the importance of

\footnotetext{
${ }^{53}$ When talking about the homeless population in the neighborhood, Geoff stated; “"'they'll be gone as long as there's enforcement, and they'll be back as soon as there's not."
} 
the neighborhood's diversity was profound. Ali identified himself as multiracial, and described Lents's diversity as a specific reason he chose to move to the neighborhood. Jameson also described the neighborhood's diversity as an important factor in his family's decision to move to the neighborhood, and spoke of the value he saw in his son being exposed to the other cultures and languages that are present in the neighborhood.

Jameson also saw the neighborhood's ethnic diversity as having an impact on the availability of culturally specific groceries there. While referring to a particular soda that he grew up drinking in Haiti, which is also available at Fubon, Jameson stated: “... I think the grocers or the supermarket owners are very sensitive of folks that are living in their neighborhood. They know what they want."

\section{Community}

Four out of five participants in Group B also mentioned community within Lents. Of those participants, two of the four felt strong that the neighborhood lacked a sense of community and community building. In contrast, two of the other participants expressed their appreciation for the sense of community within the neighborhood. Jameson, who mentioned his appreciation for the neighborhood's sense of community and support, also explained that much of this support came in the form of online forums, such as Facebook groups.

\section{Neighborhood Change}

Three of the five participants also spoke about neighborhood change during their interviews, and participant's feelings around changes were a mix of positive and 
negative. Both Amanda and Emily referenced the work that the PDC is doing in the neighborhood to bring about neighborhood improvements, and both participants expressed frustration at how slowly changes were taking place. Amanda stated that one of the reasons that she and her husband moved to Lents was because of PDC's decision to designate the areas as an urban renewal zone. For Emily and Amanda, neighborhood change was as a positive step forward. In contrast, Ali expressed concern with neighborhood changes, particularly with regard to gentrification, displacement, and affordability. During his interview Ali stated that Lents was "the pinnacle of that neighborhood that in fifteen years is gonna be a completely different place," and he speculated about how many current residents could no longer afford to live in the neighborhood, due to rising housing prices.

\section{E. Retail}

Three of the five participants also mentioned the lack of retail options in Lents. Both Amanda and Emily stated that they would like to see more shops in the neighborhood, and Jameson also mentioned the neighborhood's lack of shopping options. However, unlike Emily and Amanda, Jameson did not see the lack of shopping options within the neighborhood as a problem. Rather, he stated that "people who live here don't really care for [shopping], you go somewhere else." 


\section{Chapter 5: Discussion}

The results of my interviews with Group A and B support both of my hypotheses about food access in Lents. Overall, there was a consensus among Group A that food access within the neighborhood was a problem. However, although all participants in Group A acknowledged significant barriers to food access in the neighborhood, there was less consensus about the cause and magnitude of those barriers. Some of the participants explicitly characterized Lents as a "food desert," while others actively avoided using the term, or described the neighborhood as "a step right above" a food desert. Overall, there was a wide range of responses to what participants saw as barriers to neighborhood food access, including: transportation and mobility, price, language, and hours of operation.

Conversely, interviews with Group B revealed that residents do not overwhelmingly classify their food environment as a food insecure. Participants had a wide range of positive and negative experiences with grocery shopping in the neighborhood. Residents indicated that they face a range of barriers to accessing food within the neighborhood, including walkability, neighborhood geography, personal preferences, and crime and safety. However, the data also indicate that, generally speaking, the participants found food access in Lents to be sufficient and, in some cases, uniquely positioned to serve their individual needs. Taken as a whole, the qualitative data collected from Group B indicate that quantitative data alone do not adequately capture the complexity of residents' lived experiences with regard to food access.

Reflecting Shaw's (2006) perceptions of food access, three of the informants in Group B cited economic factors as an important influence in deciding where to shop for groceries. Similarly, attitudes towards grocery stores in the neighborhood represent a 
significant barrier for several of the people interviewed, particularly in terms of grocery store safety. Shaw defines attitude as "any state of mind that prevents the consumer from accessing foods they can otherwise physically bring into their home and have the necessary assets to procure" (Shaw 2006; 242). Two participants expressed discomfort with the safety of one of the largest grocers in the neighborhood, stating that they choose to shop at other locations in the neighborhood because of those safety concerns.

Conversely, physical barriers to accessing food were not widely addressed by the people interviewed in Group B. Only one participant referenced physical barriers to accessing food, stating that the nearest grocery store, which was a mile from her house, was too far to walk.

Additionally, the data indicate that most of the residents I interviewed make use of culturally specific and specialty grocers in and around the neighborhood. For the residents I spoke with, culturally specific and specialty stores play an important role in the neighborhood, particularly with rearguards to cost and access to specialty products. Participants in Group B supplied anecdotal evidence that, regardless of store size, the culturally specific and specialty grocers in the neighborhood often carried specific products at substantially lower prices than the major chains in the area. This finding aligns with research by Short et al. (2007), which found that small markets in San Francisco sell "culturally specific foods at substantially lower prices than nearby chain stores" (359). The data presented above indicates that the same may be true in Lents; many of the participants mentioned the lower prices and availability of specific products as a key reason they chose to shop at the neighborhood's culturally specific and specialty grocers, such as the Portland Fruit Market, Fubon, and Oriental Food Value. 
For one participant, the presence of culturally specific grocers in the neighborhood was especially meaningful. Jameson spoke at length about the fact that the neighborhood offers a unique level of access to foods that are important to both he and his wife. While they also rely on traditional grocery stores for their shopping needs, the family regularly visits Fubon, where they are able to easily access culturally specific foods. While Fubon caters to Asian shoppers, Jameson also relayed the fact that Fubon carried an unusual brand of soda that he grew up drinking in Haiti. For Jameson, finding culturally specific products in his neighborhood was profoundly meaningful, and he stated that seeing the soda at Fubon made him realize "I'm home!” As Jameson's story demonstrates, it is difficult to quantify the importance of having access to culturally specific grocers, which are often overlooked by tools like the USDA's FARA.

It is also important to note, however, that the availability of culturally specific foods in Lents does not necessarily fit the needs of all residents, which is also something Short et al. also address in their research. Lents has large Asian and Latino populations, and the grocery and corner stores in the neighborhood reflect that diversity. Several of the participants stated that they regularly visit the Asian grocers in the neighborhood, and that those locations provide access to foods residents cannot obtain elsewhere. However, as Ali pointed out, Lents does not have retailers that offer products such as Persian and Turkish spices, or Halal meat. Ali attributed this to the fact that those ethnic groups are not well represented in the neighborhood. Therefore, while Ali might prefer to shop at the Asian grocers in the neighborhood because of the cultural and ethnic diversity they provide, they also do not necessarily meet all of his specific needs. 
In addition to price, several Group B participants mentioned food quality, customer service, and safety concerns as important factors in determining where they shop. These findings align with research by a number of scholars (Shannon 2016; Coveney and O’Dwyer 2009; Latham and Moffat 2007; Zenk et al. 2005). Research by Shannon (2016), in particular, found that consumer preference is a critical, and often overlooked, aspect of food access. Several participants cited safety, customer service, and food quality as reasons why they do, or do not, shop at specific locations within the neighborhood. However, for participants in this study, quality and price were not framed as barriers to shopping, per se. Rather, they were framed as important influences of where participants chose to do their shopping.

The data indicate that the major food access barriers cited by Group A do not necessarily reflect the viewpoints of the Group B participants. Although there was significant consensus among both interview groups that the Fred Meyer at Foster and $82^{\text {nd }}$ was not ideal, participants in Group A cited price, cleanliness, and availability or organic products as the primary problems with the store, while participants in Group B primarily framed their concerns in terms of physical safety. Furthermore, participants in Group A felt that the major barriers to accessing food were language, mobility, walkability, price, and hours of operation. While these findings may be attributed to the small sample size of Group B, which did not include any non-English speakers, people without any access to a personal vehicle, or people who disclosed physical mobility challenges, they may also point to gaps in the Group A participant's perceptions of food access within the neighborhood. 
Alkon et al. (2013) criticize food access research for assuming that people simply shop at the stores that are closest and easiest for them to access. Rather, researchers like Alkon et al. and Breyer and Voss-Andreae (2013) argue that price is a more significant factor in determining shopping behaviors. The findings of this research indicate that distance to stores is less important to participants than other factors. However, this research also indicates that price alone does not explain shopping habits in the Lents neighborhood. While cost was an important factor in shopping behavior and perceptions of food access, factors such as quality, customer service, safety, and availability of specific products were also important.

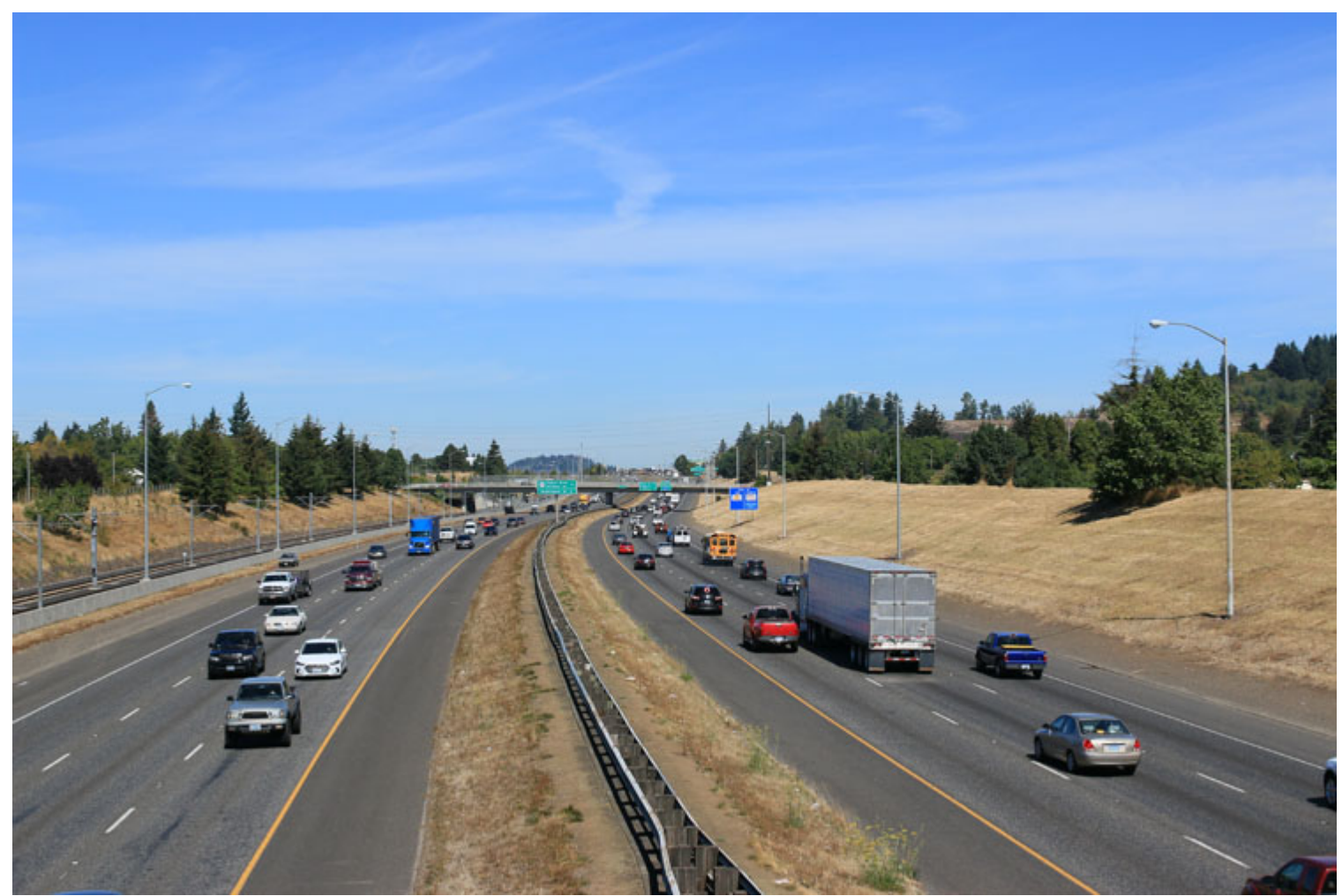

Figure 5.1 Image of the I-205 highway, as seen from the I-205 Multiuse Path. The max light rail can be seen to the left. The Multiuse pathway is one of only two pathways across I-205 within the neighborhood. 
Similarly, interviews with participants in Group B underscore the fact that people do not choose what neighborhood to live in simply based on convenient access to grocery stores. Rather, the decision to live in Lents is made based on a wide variety of factors, such as its cultural diversity, affordability, and access to public transportation. While they are not all directly related to food access in Lents, many of these issues are significantly intertwined with food access, and have a notable influence on what food is available in the neighborhood, and how easy it is to access. For example, nearly all of the participants in both study groups addressed the fact that walkability and sidewalk availability in the neighborhood is a problem (Figure 5.1). While none of the participants in Group B indicated that this was a problem for them with regard to food access, it is possible that this poses a significant barrier to neighborhood residents without a car. Participants in both Group A and Group B both believed that access to food was difficult for residents that lack access to a personal vehicle.

Overall, these findings indicate that traditional means of measuring food access through the use of quantitative tools and GIS fail to capture the lived experiences of food access. While the data provided by the USDA's FARA provides context for neighborhood food-access discussions, such maps do not provide answers to the problem of food insecurity. At present, the use of GIS represents an oversimplification and unsophisticated approach towards viewing spatial relations with regards to food access in urban environments. The data I collected underscores the importance of using qualitative data in conjunction with spatial tools such as the USDA's FARA. My research also indicates that tools such as FARA may be especially ill suited for measuring food access 
in gentrifying urban areas, since food desert models assume a level of socioeconomic stagnation not present in rapidly changing neighborhoods.

Interestingly, it was the secondary interview themes that revealed the most agreement among the two interview groups. Participants in Group A brought up the availability and affordability of retail space in Lents. Several participants in Group B also noted the lack of retail within the neighborhood, and it would be reasonable to posit that the lack of retail options (as perceived by Group B) is related to the lack of availability and affordability of spaces (and perceived by Group A). As mentioned above, nearly all participants in both groups also mentioned transportation and walkability. While neighborhood issues like walkability and housing affordability may seem tangential to the issue of food access, they speak to the same fundamental issue: the neighborhood's livability ${ }^{54}$. Concerns about present and future livability in the neighborhood are central to many of the participant's stories, and they tie in to larger structural changes currently underway not only in the neighborhood, but also in the city of Portland as a whole. As Nathan Jones of Livable Lents put it:

Portland is becoming a model for what sustainability and neighborhood and development look like worldwide.... we're one of the greenest cities, we're also one of the highest gentrifying cities, and until we're able to do it in a better, more inclusive way, we're providing a flawed model, and a model that's not just.

\footnotetext{
${ }^{54}$ Food security organizations such as the Oregon Food Bank are increasingly getting involved with issues that might seem tangential to their mission of increasing food security. For example, the Oregon Food Bank is now investing its resources in supporting minimum wage and housing policy, which has been a change of pace for the organization. Jen Turner spoke to this shift; "Hunger is a symptom of poverty, poverty has systemic factors contributing to it -- being employment, systemic racism, and housing... Our CEO testified in favor of raising the min. wage over the winter and that felt like a big moment for us, and that felt like a big moment for us in terms of policy. We have for a long time, been focused on food only, so things like tax credits for food donations, SNAP policy... super important, but still at the periphery of the actual root causes. Working on wage policy and housing policy is getting us a little close to that which has been exciting."
} 
The vast majority of the participants in Group A addressed concerns over neighborhood affordability, for both residents and neighborhood businesses. Research by Miewald and McCann (2014) found that, in Vancouver B.C., "foodie gentrification" often resulted in the displacement of affordable diners and corner shops that characterize a neighborhood. In Vancouver this also created challenges for charitable organizations, since "rising rents and gentrifier NIMBYism may increasingly constrain their abilities to provide services" (548). The same processes seem to be playing out in Lents. Small businesses and non-profits, such as SproutUp!, Green Lents, and the neighborhood farmers market, are struggling to find spaces in the neighborhood from which they can operate and do business. Overall, there was a sense of concern over who the neighborhood changes were "for", who they would benefit, and how existing services and businesses would continue to operate within the neighborhood in the coming years. Nathan Jones of Green Lents stated, “... you end up taxing these low-income people who live in this area, and then making them pay for their own displacement." These concerns were also echoed by two of the participants in Group B; however, two other participants in Group B framed neighborhood change as a reason why they choose to move to Lents in the first place. For the latter group, neighborhood change was seen as a positive step forward for the neighborhood, rather than an equity issue.

Several participants in both groups expressed doubt that, as the price of housing continues to rise, Lents will remain a haven for working class Portlanders. Most participants expressed concern about neighborhood gentrification, and an awareness of how that process has played out in other neighborhoods, such as North Portland. Survey data collected in 2012 and 2015 by Livable Lents reflect widespread neighborhood 
concern that this process will repeat itself in Southeast Portland. When Livable Lents survey participants were asked when they moved to Lents, and where in the city they had lived previously, it became evident that:

A lot of people had moved from North or Northeast Portland and inner Southeast. More people had moved from those parts than [from] another city, and ended up in Lents.... there's probably folks who have been displaced due to gentrification in other parts of Portland that are maybe now second wave, vulnerable to displacement a second time" (Nathan Jones, Livable Lents)

In conclusion, my research demonstrates that residents have a wide range of perceptions regarding food access in Lents, and many of these perceptions differ from those of the non-profits and businesses that work in the area. Although not all residents feel that their access to food is adequate, the majority of the people interviewed expressed overall satisfaction with their access to grocery stores in and around the neighborhood. Furthermore, most of the residents that were interviewed mentioned the importance of the culturally specific and specialty grocers in the neighborhood, citing price and availability of specific products as a main incentive for shopping at those locations. 


\section{Chapter 6: Conclusion}

Since the late 1990's, 'food deserts' have dominated the academic and policy literature on food access and food security. Since that time, the term has also spawned a number of related concepts, such as 'food mirage,' 'junk food jungle,' and 'food swamp' (Breyer and Voss-Andreae 2013; Everett 2011; Short et al. 2007). While food deserts may provide a useful measure for identifying food insecurity at a broad scale, they fail to account for individual definitions and perceptions of food access (Barnes et al. 2015; McEntee 2009). Food is a complex and intimate topic, and sufficient access to healthy and affordable food resources can look very different from person to person.

Furthermore, the food desert model assumes a lack of agency on the part of low-income populations. People are not simply "takers" of the nearest available food options (Alkon et al. 2013). While cost and distance may feature prominently, a host of other factors also influence perceptions of food access, including transportation access, walkability, food quality, grocery store safety, customer service, and access to specific products, to name but a few (Coveney and O’Dwyer 2009; Shannon 2016).

The research that I conducted in Lents shows a disconnect between how residents perceive their food environment, and how government, non-profit, and businesses within the neighborhood view local food access. All of the participants in Group A saw food access within the neighborhood as an issue, and the two private businesses that I interviewed framed 'food deserts' as part of their explicit business models. Two other participants in Group B, however, actively avoided using the term 'food desert' to describe the neighborhood, and one participant stated that the neighborhood was "a step right above" (Amber Holland, Portland Farmers Market) a food desert. Overall, the non- 
profits and businesses within the neighborhood reflect the narrative put forth by the USDA's FARA, which identifies the neighborhood as a food desert.

Conversely, residents' perceptions of food access within the neighborhood varied much more widely than those of Group A. One participant described the neighborhood as a "food village," while others expressed concern over availability and distance of food retailers. Two of the five participants in Group B felt that distance was not an issue, while one participant felt that distance was a problem. Two other participants did not express that distance was a barrier for them, personally, but stated that it was an issue "relative to where you live" (Geoff, Group B) in the neighborhood. When asked if they felt their neighborhood has adequate access to food retail locations, two of the five participants stated that they felt they were adequate, while one felt that they were not. The other two participants also expressed that, while the issue did not impact them personally, they felt that food resources within the neighborhood were not adequate, due to affordability issues, lack of appropriate food choices, and the time constraints for a working class community.

This conflict supports Alkon et al.'s (2013) assertion that using binary measures to categorically label spaces food (in)secure can mask individual experience, imposing a definition of access or inaccess on a population. While some residents in the neighborhood felt strongly that distance and availability were significant barriers to food access - thus aligning with the overall viewpoints of Group A—others did not feel that those factors presented a challenge, or felt that they might be an issue for other people within the neighborhood, but not for themselves. 
Furthermore, my research supports the assertion that ethnic and specialty grocers are a critical element of the foodscape in Lents, and are likely being overlooked in other areas identified as food insecure. Ethnic and specialty grocers are often missed as critical food resources, particularly within GIS-based food access research (Ma et al. 2013). Interviews with residents in the neighborhood (Group B) reveal significant reliance on culturally specific and specialty grocers in and around Lents, and participants frequently mentioned the availability of specific goods and lower prices as a reason they rely on those stores. For participants that identified as POC, the ethnic grocery stores were particularly important; this was especially true in interviews with Jameson.

\section{Limitations and Future Directions}

There are several limitations to this study, including sample size, the lack of representation for all neighborhood quadrants, and lack of monetary compensation for participants' time. Because a sample size of 12 is relatively small, this research is best viewed as exploratory, and cannot be used to make definitive statements about the foodscape of Lents. Additionally, none of the participants in Group B were renters, and none of them lived in the southeast quadrant of the neighborhood. Furthermore, participants had higher incomes than the neighborhood's median family income, which was $\$ 34,508$ in 2014 (Brunelle et al. 2016). Therefore, the sample group for Group B cannot be considered representative of the neighborhood as a whole.

The findings of this preliminary study indicate that residents may feel differently about their food access based on what past of the neighborhood they live in. This is an area ripe for further study, especially if a significantly larger sample size could be 
obtained. Interviews also revealed that grocery shopping habits are highly dependent on a large number of factors, including safety, price, quality, convenience, and personal preference. As such, there is also significant potential to further explore what factors help to shape and determine participants' shopping habits. Additionally, participants were not compensated for the time they generously set aside to be interviewed. While every effort was made to make the interview process as convenient as possible, funding for interview compensation might help to recruit more participants, and encourage participation by people lower on the socioeconomic spectrum.

As many participants noted, Lents is currently in a state of change, as housing prices rise and the neighborhood is faced with decisions about its future. New businesses, including a grocery store, have also opened up in and around the neighborhood within the last year. As such, neighborhood food access - and perceptions of that food accesshave the potential to change dramatically in the next five to ten years, depending on the scope of economic development in the neighborhood. As such, a follow-up study would be advisable. Furthermore, many participants in Group B mentioned factors other than price and distance as barrier to food access, including; quality, customer service, safety, and availability of specific foods. While several other studies have shown that similar attributes are important factor in measuring food access (Shannon 2016; Coveney and O’Dwyer 2009; Latham and Moffat 2007; Zenk et al. 2005), there is significant potential for additional research in this area. 


\section{References}

Abusabha, R., D. Namjoshi, and A. Klein. 2011. Increasing Access and Affordability of Produce Improves Perceived Consumption of Vegetables in Low-Income Seniors. Journal of the American Dietetic Association 111: 1549-1555.

Agyeman, J. and J. McEntee. 2014. Moving the Field of Food Justice Forward Through the Lens of Urban Political Ecology. Geography Compass 8(3): 211-220.

Alkon, A., D. Block, K. Moore, C. Gillis, N. DiNuccio, and N. Chavez. 2013. Foodways of the urban poor. Geoforum 48: 126-135.

Barnes, T.L., B.A. Bell, D.A. Freedman, N. Colabinchi, and A.D. Liese. 2015. Do people really know what food retailers exist in their neighborhood? Examining GISbased and perceived presence of retail food outlets in an eight-county region of South Carolina. Spatial and Spatio-temporal epidemiology 13: 31-40.

Bates, L.K. 2013. Gentrification and Displacement Study: implementing an equitable inclusive development strategy in the context of gentrification. City of Portland, Bureau of Planning and Sustainability.

Beaulac J., E. Kristjansson, and S. Cummins. 2009. A systematic review of food deserts, 1966-2007. Preventing Chronic Disease 6(3): A105. Available at http://www.cdc.gov/pcd/issues/2009/jul/08_0163.htm (last accessed 4 November 2014).

Becker, T. 2015. Is Lents Portland's up-and-coming neighborhood? KOIN 6. Available at http://koin.com/2015/12/30/is-lents-portlands-up-and-coming-neighborhood/ (last accessed 26 August 2016).

Blanchard, T.C. and T.L. Matthews. 2007. Retail concentration, food deserts, and fooddisadvantaged communities in rural America. In Remaking the North American Food System-Strategies for Sustainability, ed. C.C. Hinrichs and T.A. Lyson, 201215. Lincoln, NE: University of Nebraska Press.

Bodor, J.N., D. Rose, T.A. Farley, C. Swalm, and S.K. Scott. 2007. Neighborhood fruit and vegetable availability and consumption: the role of small food stores in an urban environment. Public Health Nutrition 11(4): 413-420.

Braun, V. and V. Clarke. 2006. Using thematic analysis in psychology. Qualitative Research in Psychology 3(2): 77-101.

Breyer, B. and A. Voss-Andreae. 2013. Food mirages: geographic and economic barriers to healthful food access in Portland, Oregon. Health and Place 24: 131-139. 
Brunelle, A., D. DeVitis, C. Groecki, C. Lust, K. Sellin, and J. Todoroff. 2016. Lents strong: community action plan for a livable, affordable neighborhood. Master of Urban and Regional Planning Workshop Projects. Paper 131. Available at http://pdxscholar.library.pdx.edu/usp_murp/131 (last accessed 12 October 2016)

Cedar Lake Ventures Inc. 2016. Statistical Atlas. San Francisco, CA. Available at StatisticalAtlas.com (last accessed 26 August 2016).

Canton, S., R. Engler-Stringer, N. Muhajarine. 2015. Characterizing Saskatoon's food environment: a neighbourhood-level analysis of in-store fruit and vegetable access. Canadian Journal of Urban Research 24(1): 62.

Capsi, C.E., I. Kawachi, S.V. Subramanian, G. Adamkiewicz, and G. Sorensen. 2012. The relationship between diet and perceived and objective access to supermarkets among low-income residents. Social Science and Medicine 75: 1254-1262.

Carro-Figueroa, V. and A. Guptill. 2007. Emerging farmers' markets and the globalization of food retailing: a perspective from Puerto Rico. In Remaking the North American Food System, ed. C.C. Hinrichs and T.A. Lyson, 260-276. University of Nebraska Press: Lincoln, NE.

Cerovečki, I.G., and M. Grünhagen. 2016. "Food deserts" in urban districts: evidence from a transitional market and implications for macromarketing. Journal of Macromarketing, 36(3): 337-353.

Chen, D., E.C. Jaenicke and R.J. Volpe. 2016. Food Environments and Obesity: household diet expenditure versus food deserts. American Journal of Public Health Research 106(5): 881-888.

City of Portland. 2012. City of Portland - Unpaved Streets. Available at https://www.portlandoregon.gov/cbo/article/394815 (last accessed 9 October 2016).

Coveney, J. and L.A. O’Dwyer. 2009. Effects of mobility and location on food access. Health and Place 15: 45-55.

Cummins, S. and S. Macintyre. 2002. "Food deserts"-evidence and assumption in health policy making. $B M J 325: 436-438$.

ERS and USDA (Economic Research Service and United States Department of Agriculture). 2014. Food Access Research Atlas. Available at http://www.ers.usda.gov/data-products/food-access-research-atlas.aspx (last accessed 10 November 2016). 
Elitzak, H. 2015. Retail trends. United States Department of Agriculture, Economic Research Service. Available at http://www.ers.usda.gov/topics/food-marketsprices/retailing-wholesaling/retail-trends.aspx (last accessed 24 June 2016).

Everett, M. 2011. Practicing anthropology on a community-based public health coalition: lessons from HEAL. Annals of Anthropological Practice 35(2): 10-26.

Franco, M., A.V. Diez Roux, T.A. Glass, B. Caballero, and F.L. Brancati. 2008. Neighborhood Characteristics and Availability of Healthy Foods in Baltimore. American Journal of Preventative Medicine 35(6): 561-567.

Galvez, M.P., K. Morland, C. Raines, J. Kobil, J. Siskind, J. Godbold, and B. Brenner. 2007. Race and food-store availability in an inner-city neighborhood. Public Health Nutrition 11(6): 624-631.

Glanz, K., J.F. Sallis, B.E. Saelens, and L.D. Frank. 2007. Nutrition environment measures survey in stores (NEMS-S): Development and evaluation. American Journal of Preventative Medicine 32(4): 282-289.

Gillespie, G., D.L. Hilchey, C.C. Hinrichs, and G. Feenstra. 2007. Farmers' markets as keystones in rebuilding local and regional food systems. In Remaking the North American Food System-Strategies for Sustainability, eds. C.C. Hinrichs and T.A. Lyson, 65-83. Lincoln, NE: University of Nebraska Press.

Green Lents. 2016. Livable Lents Community Listening Project: 2015 Outreach Report. Available at http://livablelents.org/wp-content/uploads/2014/08/Livable-Lents2015-Final-Report-.pdf (last accessed 26 August 2016).

Griffin, A. 2013. Portland study targets neighborhoods next up for gentrification. The Oregonian. Available at http://www.oregonlive.com/portland/index.ssf/2013/06/portland study targets ne ighbo.html (last accessed: 26 August 2016).

Goodling, Erin, J. Green, and N. McClintock. 2015. Uneven development of the sustainable city: shifting capital in Portland, Oregon. Urban Geography 36(4): $504-527$.

Gordon, C., M. Purciel-Hill, N.R. Ghai, L. Kaufman, R. Graham, and G.Van Wye. 2011. Measuring food deserts in New York City's low-income neighborhoods. Health \& Place 17: 696-700.

Gottlieb, R. and A. Joshi. 2013. Food Justice. Second Edition. United States: MIT Press. 
Gulizia, A., K. Kibler, V. Meyer, R. Stavenjord, and M. Steele. 2006. Destination: Lents. Master of Urban and Regional Planning Workshop Projects. Paper 4. Available at http://pdxscholar.library.pdx.edu/usp_murp/4 (last accessed 24 August 2016).

Guthman, J. 2008. Bringing good food to others: investigating the subjects of Alternative food practice. Cultural Geographies 15(4): 431-447.

Hendrickson, M., W.D. Heffernan, P.H. Howard, and J.B. Heffernan. 2001. Consolidation in food retailing and dairy: implications for farmers and consumers in a global food system. Report. Washington D.C.: National Farmers Union. Available at http://www.foodcircles.missouri.edu/whstudy2.pdf (last accessed 18 November 2016).

Hernandez, T. 2016. No more serenity at Portland homeless camp on Springwater Corridor. The Oregonian. Available at http://www.oregonlive.com/portland/index.ssf/2016/07/no more serenity at sout heast.html (last accessed 26 August 2016).

Komakech, M.C.D., and S.J. Jackson. 2016. A study of the role of small ethnic retail grocery stores in urban renewal in a social housing project, Toronto, Canada. Journal of Urban Health: Bulletin of the New York Academy of Medicine 93(3): 414-424.

Koro, M.E., S. Anandan, and J.J. Quinlan. 2010. Microbial quality of food available to populations of differing socioeconomic status. American Journal of Preventative Medicine 38(5): 478-481.

Latham, J. and T. Moffat. 2007. Determinants of variation in food cost and availability in two socioeconomically contrasting neighbourhoods of Hamilton, Ontario, Canada. Health and Place 13: 273-287.

Lawson, L.J. 2005. City Bountiful-A Century of Community Gardening in America. Berkeley, CA: University of California Press.

Lee, H. 2012. The role of local food availability in explaining obesity risk among young school-aged children. Social Science and Medicine 74: 1193-1203.

Leete, L., N. Bania, and A. Sparks-Ibanga. 2012. Congruence and convergence: alternative approaches to identifying urban food deserts and food hinterlands. Journal of Planning Education and Research 32(2): 204-218.

Leinberger, C.B. 2005. Turning around downtown: twelve steps to revitalization. Washington, DC: Brookings Institution Center on Urban and Metropolitan Policy. 
Ma, X., S.E. Battersby, B.A. Bell, J.D. Hibbert, T.L. Barnes, and A.D. Liese. 2013. Variation in low food access areas due to data source inaccuracies. Applied Geography 45: 131-137.

Martinez, S.W. 2007. The U.S. Food Marketing System: Recent Developments, $1997-$ 2006, EER-42. U.S. Department of Agriculture, Economic Research Service.

McClintock, N. 2011. From Industrial Garden to Food Desert: Demarkated Devaluation in the Flatlands of Oakland, California. In Cultivating Food Justice: Race, Class, and Sustainability, eds. A. Alkon and J. Agyeman. 89-120. MIT Press: United States.

McClintock, N., D. Mahmoudi, M. Simpson, and J. Pereira Santos. 2016. Socio-spatial differentiation in the Sustainable City: A mixed-methods assessment of residential gardens in metropolitan Portland, Oregon, USA. Landscape and Urban Planning $148,1-16$.

McEntee, J. 2016. Highlighting food inadaquacies: does the food desert metaphor help this cause? British Food Journal 111(4): 349-363.

Mesh, A. 2014. Razed \& confused. Willamette Week. Available at http://www.wweek.com/portland/article-21792-razed-confused.html (last accessed 24 April 2016).

Michimi, A. and M.C. Wimberly. 2010. Associations of supermarket accessibility with obesity and fruit and vegetable consumption in the conterminous United States. International Journal of Health Geographies 9(49): 1-14.

Nelson/Nygaard Consulting Associates Inc. 2012. Foster corridor transportation existing conditions \& opportunities: preliminary assessment. Available at https://www.portlandoregon.gov/transportation/article/416314 (last accessed 21 September 2016).

Office of Neighborhood Involvement. 2011. 2000 and 2010 Census Profile: Lents. City of Portland. Available at https://www.portlandoregon.gov/oni/article/375977 (last accessed 2 November 2016).

Ortega, A.N., S.L. Albert, M.Z. Sharif, B.A. Langellier, R.E. Garcia, D.C. Glik, R. Brookmeyer, A.M. Chan-Golston, S. Friedlander, and M.L. Prelip. 2015. Proyecto MercadoFRESCO: A Multi-level, Community-Engaged Corner Store Intervention in East Los Angeles and Boyle Heights. Journal of Community Health 40(2): 347-356. 
Padilla, C. and M.A. Eastlick. 2009. Exploring urban retailing and CBD revitalization strategies. International Journal of Retail \& Distribution Management 37(1): 723.

Payne, G.H., S.D. James, L. Hawley, B. Corrigan, R.E. Kramer, S.N. Overton, R.P. Farris, and Y. Wasilewski. 2015. CDC's health equity resource toolkit: disseminating guidance for state practitioners to address obesity disparities. Health Promotion Practice 16(1): 84-90.

Pearson, T., J. Russell, M.J. Campbell, and M.E. Barker. 2005. Do 'food deserts' influence fruit and vegetable consumption?-a cross-sectional study. Appetite 45: 195-197.

Pollan, M. 2008. In defense offood: an eater's manifesto. New York, NY: Penguin Books.

Portland State University. 1993. Lents: a Neighborhood Issues Analysis. Master of Urban and Regional Planning Workshop Projects. Paper 116. Available at http://pdxscholar.library.pdx.edu/usp_murp/116 (last accessed 24 August 2016).

Riley, S.S. 2003. Ecology is a sistah's issue too: the politics of emergent Afrocentric ecowomanism. In This sacred earth: religion, nature, environment, ed. R.S. Gottlieb, 412-427. New York, NY: Routledge Press.

Rolling Oasis Grocers. 2015. Home page. Available at https://www.rollingoasis.com/home/. (last accessed 9 October 2016).

Roth, S. 2016. Nowhere to go: Springwater homeless sweep begins. KGW Online. Available at http://www.kgw.com/news/local/homeless/homeless-sweep-on-thespringwater-corridor/311955609 (last accessed 18 November 2016).

Ruopeng, A., and R. Sturm. 2012. School and Residential Neighborhood Food Environment and Diet Among California Youth. American Journal of Preventative Medicine 42(2): 129-135.

Saldana, J., 2009. Coding Manual for Qualitative Researchers. London: Sage Publications.

Shannon, J. 2016. Beyond the supermarket solution: linking food deserts, neighborhood context, and everyday mobility. Annals of the American Association of Geographers 106(1): 186-202.

Sharkey, T. and K. Stiegert. 2006. Impacts of nontraditional food retailing supercenters on food price changes. Food systems research group, department of agriculture and applied economics, University of Wisconsin-Madison, FSRG Monograph 
Series No. 20. Available at

https://www.aae.wisc.edu//srg/publications/Monographs/20supercenterfeb06.pdf (last accessed 12 September 2016).

Shaw, H.J. 2006. Food deserts: towards the development of a classification. Geografiska Annaler: Series B, Human Geography 88(2): 231-247.

Shobe, H. and G. Manser. 2016. Food access and affordability in the Foster Green EcoDistrict: Lessons from student engagement with equity and sustainability in southeast Portland. In Sustainable Solutions: University-Community Partnerships, eds. B.D. Worthman-Galvin, B.D., J. Allen and J. Sherman, 99-111. Greenleaf: Sheffield, UK.

Short, A., J. Guthman, and S. Raskin. 2007. Food deserts, oases, or mirages? Small markets and community food security in the San Francisco Bay area. Journal of Planning Education and Research 26 (3): 352-364.

Smith, E.E. 2016. Springwater camp saga pokes old wounds: 'Nobody's doing anything because it's Lents'. The Oregonian. Available at http://www.oregonlive.com/portland/index.ssf/2016/08/lents springwater homele ss swe.html (last accessed 26 August 2016).

Song, H.J., J. Gittelsohn, M. Kim, S. Suratkar, S. Sharma, and J. Anliker. 2009. A corner store intervention in a low-income urban community is associated with increased availability and sales of some healthy foods. Public Health Nutrition 12(11): 2060-2067.

Templeton, A. 2016. Lents residents protest Portland mayor's camping policy. Oregon Public Broadcasting. Available at http://www.opb.org/news/article/homelesscamping-portland-lents-protest/ (last accessed 26 August 2016).

Tesch, R. 1990. Qualitative research: analysis types and software tools. New York, NY: Falmer.

U.S. Congress. 2008. Food, Conservation, and Energy Act of 2008. Public Law 110-246.

Ver Ploeg, M., V. Breneman, T. Farrigan, K. Hamrick, D. Hopkins, P. Kaufman, B.H. Lin, M. Nord, T. Smith, R. Williams, K. Kinnison, C. Olander, A. Singh, E. Tuckermanty, R. Krantz-Kent, C. Polen, H. McGowan, and S. Kim. 2009. Access to Affordable and Nutritious Food: Measuring and Understanding Food Deserts and Their Consequences. Report to Congress. Administrative Publication No. AP036 . 
Walker, R.E., C.R. Keane, and J.G. Burke. 2010. Disparities and access to healthy food in the United States: a review of food deserts literature. Health and Place 16: 876884.

Wang, M.C., C. Cubbin, D. Ahn, and M.A. Winkleby. 2007. Changes in neighbourhood food store environment, food behaviour and body mass index, 1981-1990. Public Health Nutrition 11(9): 963-970.

Zenk, S.N, A.J. Schulz, T. Hollis-Neeley, R.T. Campbell, N. Holmen, G. Watkins, R. Nwankwo, and A. Odoms-Young. 2005. Fruit and Vegetable Intake in African Americans - Income and Store Characteristics. American Journal of Preventative Medicine 29(1): 1-9.

Zwiebach, E. 2015. 2015 Top 75: The Big Picture. SN: Supermarket News. Available at http://supermarketnews.com/rankings-research/2015-top-75-big-picture (last accessed 11 June 2016). 
Appendix A: Map of Lents-Area Grocers

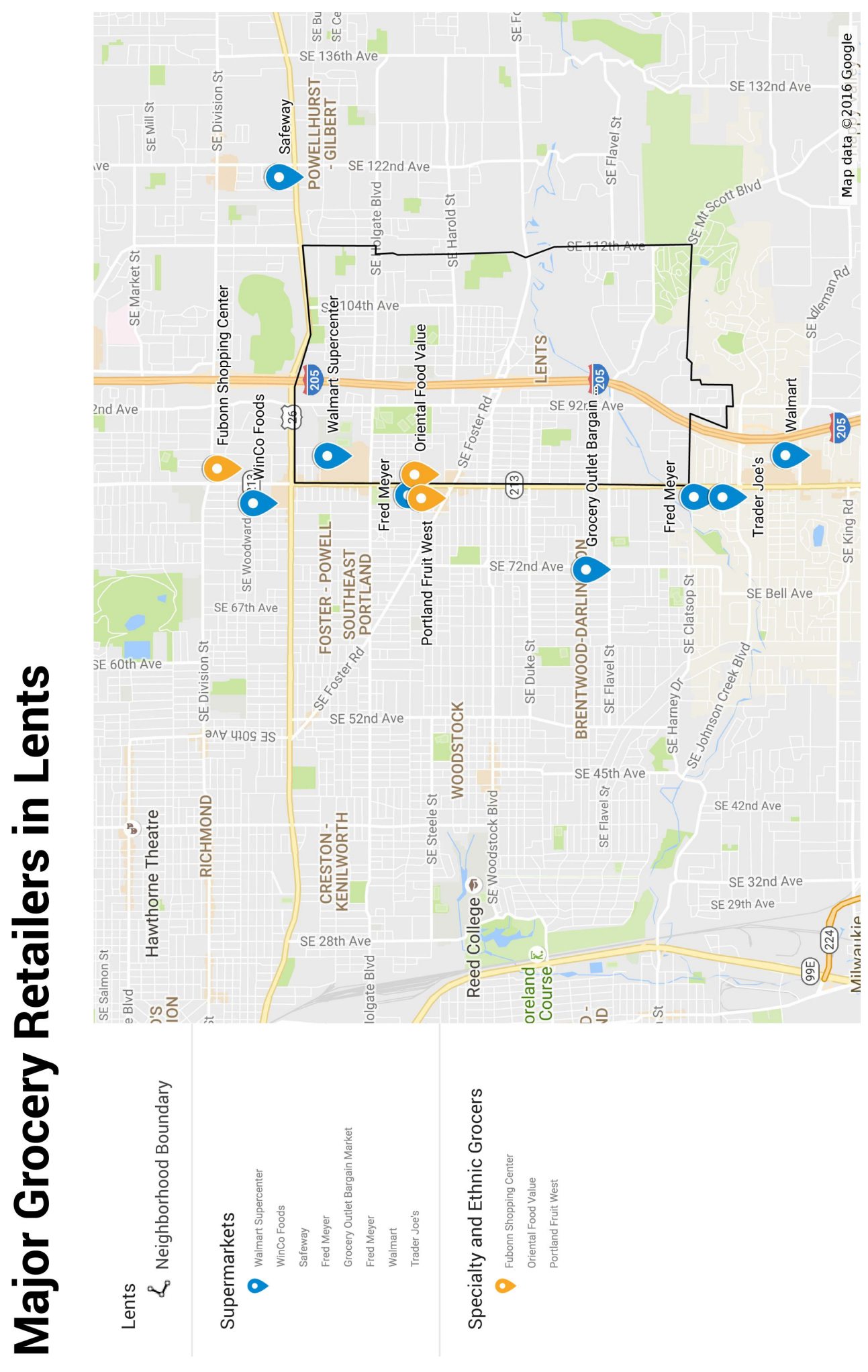




\section{Appendix B: Interview Questions, Group A}

\section{Interview Guide for Non-Profit Entities and Community Organization Participants}

1. Tell me about yourself. What is your education and work background? How long have you been involved with [NON-PROFIT NAME]. How and why did you get involved?

2. Tell me about [NON-PROFIT NAME]'s work. When, how, and why were you founded?

3. What is the mission of your organization? How do you accomplish that mission?

4. Describe the neighborhood that you serve. What is unique about the community you're in?

5. How do you define "food justice"? Is this language you use in your organization?

6. What is the food environment of your community like? Do you think community members have adequate food access? Why or why not? (if applicable: what are you doing to address these issues?)

7. How does [NON-PROFIT'S NAME] engage with the local community? What type of outreach do you do?

8. In terms of demographics, who do you typically serve? What is your target audience?

9. Do you encounter any challenges with regards to reaching your target audience? Why or why not?

10. Where does your funding come from? Has funding shaped your organization's goals? If so, how? 


\section{Appendix C: Interview Questions, Group B}

\section{Interview Guide for Community Member Participants}

Thank you for participating in this research project on food access in Portland! The aim of this interview is to get a better sense of where and how people shop and eat, and the barriers that may exist to accessing food. If you have any questions during the interview, please don't hesitate to ask! Just as a reminder, participation in this interview is completely voluntary, and you can stop the interview at any time. At the end of this interview, I will also give you a short survey to fill out.

\section{General:}

1. Tell me a little about yourself. What you do for a living? How long have you lived in Portland?

2. What part of the city do you currently live in? Can you describe your neighborhood? How long have you lived there?

3. What do you like about your current neighborhood? What do you dislike?

4. What do you wish your neighborhood had more of (i.e. parks, shops, schools, public transportation, etc.)? Why?

\section{Food Access:}

I'm now going to ask you a series of questions about where you shop, why, and how.

1. How do you typically get to the store to do your grocery shopping?

2. Do you have access to a car?

3. How often do you shop for groceries and food goods?

4. Where do you typically shop? Do you typically buy food within your neighborhood, or outside of it? Why?

5. What do you typically buy each week?

6. Do you regularly visit any specialty grocery stores, bakeries, or butchers? Where?

7. Are there any goods that you would like to purchase, but have difficulty accessing (such as culturally specific foods, or fresh produce)?

8. Are there any barriers that prevent you from shopping as often as you would like, or at the locations that you were prefer?

9. Do you have a personal or community garden plot? Why or why not?

10. Do you participate in a CSA (community supported agriculture) program?

11. Do you get food from anywhere other than conventional grocery stores, such as a food pantry or church? Can you tell me more about that?

\section{Food Access and Health:}

I'm now going to ask you a series of questions about your perceptions about food access and health.

1. How do you define "healthy" food? What does a balanced diet mean to you?

2. Do you feel you have a balanced diet? Why or why not?

3. Do you cook? Why or why not? How often do you cook? 
4. Do you think your community has adequate access to food retail locations? Why or why not?

5. Do you feel that distance to food stores is a barrier to grocery shopping in your community? 


\section{Appendix D: Survey, Group B}

\section{Survey for community member participants (to be completed after interviews)}

This survey will help us gather more information, allowing us to better assess who is participating in these interviews. As with the interview process itself, your participation in this survey is completely voluntary, and you may stop at any time. This data will remain confidential, and no identifying information will be used in any published material.

1. What is your gender?

2. What is your age?

3. What is your zip code?

4. What is the highest level of education you have completed? Check one.

Some high school (no diploma)

High school diploma/GED

Some college

Trade school or associated degree

Bachelor's degree

Graduate degree

None of the above/Other (please specify):

5. What best describes your race/ethnicity? Check all that apply.

Hispanic/Latino

Black/African American

Asian/Asian American

Native Hawaiian/Pacific Islander

Native American/Alaskan Native

White/Caucasian

Other (please specify):

6. What was your annual household income bracket last year? Check one.

$\$ 0-\$ 14,999$

$\$ 15,000$ - $\$ 24,999$

$\$ 25,000-\$ 34,999$

$\$ 35,000$ - $\$ 49,999$

$\$ 50,000$ - $\$ 74,999$

$\$ 75,000$ - $\$ 99,999$

$\$ 100,000$ - $\$ 149,999$

$\$ 150,000$ or more

7. Do you rent or own your current home? 
$\begin{array}{ll}\square & \text { Rent } \\ \square & \text { Own } \\ \square & \text { Other (please specify): }\end{array}$

8. Including yourself, how many people live in your current household?

9. What best describes the current residents of your household?

Couple without kids

$\square \quad$ Couple with kids

$\square \quad$ Extended family

$\square \quad$ Single adult with kids

$\square \quad$ Single adult without kids

$\square \quad$ Group of housemates

$\square \quad$ Other (please specify):

10. Do you receive Supplemental Nutrition (SNAP/"food stamps"), Women, Infants, and Children (WIC), free or reduced school lunch, or food vouchers?

Yes

$\square \quad$ No

$\square \quad$ I'm not sure 